\begin{tabular}{|c|l|}
\hline Title & Estimating the three dimensional structure of canopy foliage based on the light measurements in a Betul a ermanii stand \\
\hline Author(s) & $\begin{array}{l}\text { Kubo, Takuya; Kobay ashi, Tsuy oshi; Kato, Kyoko; Nishimura, Seiichi; U emura, Shigeru; Ono, Kiyomi; Sumida, } \\
\text { A kihiro; Hara, Toshihiko }\end{array}$ \\
\hline Citation & $\begin{array}{l}\text { Agricultural and Forest Meteorology, 148(8-9), 1293-1304 } \\
\text { https://doi.org/10.1016/.agrformet.2008.03.008 }\end{array}$ \\
\hline Issue Date & 2008-07-04 \\
\hline Doc URL & http://hdl.handle.net/2115/34680 \\
\hline Type & article (author version) \\
\hline File Information & moshiri2007.pdf \\
\hline
\end{tabular}

Instructions for use 


\title{
Estimating the three-dimensional structure of canopy foliage based on the light measurements in a Betula ermanii stand
}

\author{
Takuya KUBO ${ }^{\mathrm{a}, 1}$, Tsuyoshi KOBAYASHI ${ }^{\mathrm{b}}$, Kyoko KATO ${ }^{\mathrm{c}}$, \\ Seiichi NISHIMURA ${ }^{\mathrm{d}}$, Shigeru UEMURA ${ }^{\mathrm{e}}$, Kiyomi $\mathrm{ONO}^{\mathrm{c}}$, \\ Akihiro SUMIDA ${ }^{\mathrm{c}}$, and Toshihiko HARA ${ }^{\mathrm{c}}$
}

a Graduate School of Environmental Earth Science, Hokkaido University, Sapporo, Hokkaido 060-0810, Japan

b Faculty of Agriculture, Kagawa University, Mikicho, Kagawa 761-0795, Japan

c Institute of Low Temperature Science, Hokkaido University, Sapporo, Hokkaido 060-0819, Japan

d National Institute for Agro-Environmental Sciences, Tsukuba, Ibaraki 305-8604, Japan

e Uryu Experimental Forest, Hokkaido University, Nayoro, Hokkaido 096-0071, Japan

Keywords: canopy structure; evapotranspiration; foliage configuration; LAI; Markov Chain Monte Carlo; photosynthesis.

(MS submitted to Agricultural and Forest Meteorology on March 5, 2007)

1 Corresponding author. Tel: +81-11-706-2268;

fax: +81-11-706.4954;

E-mail address: kubo@ees.hokudai.ac.jp (T. Kubo) 


\section{Abstract}

In order to more accurately evaluate the functional activity of forest stands by canopy production and evapotranspiration, we improved the methods for field measurements and statistical modeling to estimate foliage configuration (spatial distribution of leaves) while simultaneously reconstructing the three-dimensional photosynthetically active photon flux density (PPFD) distribution (PPFD pattern) in a forest canopy. By using a sensor (photodiode) array, a PPFD pattern was observed in summer 2002 under the canopy in an even-aged, pure stand of Japanese mountain birch Betula ermanii Cham. (17-year-old) in Hokkaido, northern Japan. A Markov Chain Monte Carlo (MCMC) sampling technique is developed such that a set of foliage configurations generated by the model referred to as the Gibbs foliage canopy (GFC) approximates the field-measured PPFD pattern. The posterior distribution of the foliage configurations is generated by the parallel tempering MCMC of eight independent series of foliage configurations. The GFC model generated the posterior distribution of the LAI estimates (mean 4.56) that appeared to be appropriate in comparison to other LAI estimates of the B. ermanii stand based on the indirect and nondestructive methods by LAI-2000 (LAI = 3.43) and litterfall traps (LAI = 5.56) because they could be under- and overestimated, respectively. Our evaluations 
of the canopy production and evapotranspiration rates suggest that the relationship between LAI and canopy functions was not very simple because it depended on the nonlinear functional forms of the leaf responses of photosynthesis and transpiration to PPFD. The current study demonstrates an application of MCMC techniques that can generate a set of possible structures of unobserved/unobservable objects based on the high resolution data set obtained by some indirect (or remote-sensing) methods. 


\section{Introduction}

A three-dimensional canopy structure contains essential information to characterize a forest ecosystem, since a canopy structure is generated by local abiotic-biotic interactions and inter-/intra-specific competition among plants and animals in the forest. Moreover, since a canopy structure itself controls the functions of the forest stand such as canopy production and evapotranspiration, the indirect estimation of these functional activities of the forest stand requires a complicated data set. For instance, three-dimensional distribution of photosynthetically active photon flux density (PPFD), three-dimensional configuration of leaves, and photosynthetic performance at each leaf may be required for the estimation of canopy production. Due to the difficulty in collecting these field data, the three-dimensional information is often replaced by some easily obtainable simplified indices that can express the canopy structure. Such indices are frequently used in the field of forest ecology, although Ishii et al. (2004) stressed upon the importance of the three-dimensional structural attributes of forest stands and contended that the goal of the study of canopy structures should not be to develop a single index of stand structural complexity.

In the field of forest ecology, leaf area index (LAI), which is originally defined 
as the total one-sided area of photosynthetic tissue per unit ground surface area, is frequently adopted to represent the three-dimensional canopy structure. Jonckheere et al. (2004) and Weiss et al. (2004) are recent comprehensive reviews on the theories and methodologies to estimate LAI, such as destructive sampling, indirect measurement by photo sensors, the application of allometric relationships, and the bias correction in LAI estimation. Since LAI is regarded as one of the most appropriate indices to represent the canopy structure, it plays important roles in many models to evaluate canopy production and canopy gas exchange. For instance, in a forest stand simulator, FOREST-BGC, all the important processes such as the rates of photosynthesis, transpiration, and snow melting are functions of LAI (Running and Coughlan, 1988; Waring and Running, 1998).

It has been argued that the LAI estimate obtained by the indirect method based on ground measurements, such as gap fraction, is strongly affected by neglected factors of the canopy, such as foliage clumping (e.g. Kira et al., 1969; Gower and Norman, 1991; Dufrêne and Bréda, 1995; Cutini et al., 1998; Nilson, 1999), nonetheless, LAI has popularly been estimated by indirect optical methods (Nilson, 1999), particularly, the LAI-2000 (Li-Cor, Lincoln, NE, USA) method. This method is based on two assumptions of the canopy structure (Jonckheere et al., 2004): light blocking plant elements are randomly distributed in the canopy; and plant elements have the 
same projection as simple geometrical convex shapes. Since these assumptions were made for convenience and caused the underestimation of LAI, considerable research has been carried out to estimate the degree of discrepancy and to correct the systematic bias (e.g. Gower and Norman, 1991; Dufrêne and Bréda, 1995; Cutini et al., 1998; Nilson, 1999).

The studies on the bias correction in LAI estimates based on the ground measurements demonstrate that LAI estimation under the assumptions of homogeneous canopies are often insufficient to characterize heterogeneous forest canopies. Therefore, the techniques for directly measuring and modeling the structural complexity of the forest canopy have been extending the possibility of more accurate data analysis. For example, Sumida $(1993 ; 1995)$ measured the three-dimensional canopy structure of broad-leaved forests by using the probe cylinder method (PCM), which is a variation of point-grid sampling in the forest, although the method was not for estimating the spatial distribution of individual leaves. Fukushima et al. (1998) directly counted the three-dimensional distribution of leaf number within a large scaffolding (15 $\mathrm{m} \times 15 \mathrm{~m}$ width and $22 \mathrm{~m}$ height) in a mature broad-leaved forest and discussed the accuracy of the estimation of the vertical distribution of foliage based on ground-based measurements. Since airborne laser scanner (Lidar) is a new possible candidate for directly measuring the three-dimensional structure, a cor- 
relation analysis between the estimates of canopy properties based on Lidar and ground-based measurements were performed by Riaño et al. (2004).

One of the recent trends in the modeling of canopy production estimation is to apply the spatially explicit simulations of the three-dimensional PPFD distributions (PPFD pattern) under three-dimensional heterogeneous foliage configurations. Knyazikhin et al. (1997) developed an accurate calculation method to simulate three-dimensional radiation in a vegetation canopy of a small area by applying transport theory. The canopy model developed by Röhrig et al. (1999) evaluated the three-dimensional light interception in which the heterogeneous forest canopy was subdivided into cubic units that were either empty or occupied by a constant leaf area density. In addition to the modeling of the forest canopy, several kinds of three-dimensional canopy models were developed and validated by comparison with the corresponding field data (e.g. Cescatti, 1997a; Cescatti, 1997b). Muraoka and Koizumi (2005) evaluated the seasonal changes in the photosynthetic rate of shoots in several types of canopy trees such as Betula ermanii and Quercus crispula by using the Y-plant simulator (Pearcy and Yang, 1996; Muraoka et al., 2003). A modeling and validation study was carried out by Wang et al. (2006), in which the change in the diffuse photosynthetically active radiation (DPAR) during the daytime was simulated based on the field measurements obtained in a Zea mays field. 
On the other hand, the statistical modeling of the structures and functions of the three-dimensional canopy is still insufficient with some exceptions. Ogle et al. (2004) developed a Bayesian model to analyze (not the forest canopy, but) plant root systems so that the root structures were statistically reconstructed by the Markov Chain Monte Carlo (MCMC) method based on field experimental data. Although there have been a few pioneering works to statistically reconstruct tree or forest canopies (e.g. Giuliani et al., 2005) based on field measurements, there is a need to develop additional statistical methods that may yield the likelihood of the estimated foliage configurations and the confidence intervals of the estimates of the properties of a plant community, such as the canopy structure and functions.

In the current study, we attempted to improve the methods for field measurements and statistical modeling to estimate the foliage configuration while simultaneously reconstructing the PPFD pattern in a forest canopy. First, we measured the PPFD pattern by using a photosensor array of small photodiodes (Nishimura and Itoh, 2003) under the canopy of a dense secondary forest stand of Betula ermanii in northern Japan where a long-term field experiment is ongoing (Takahashi et al., 2002, 2003; Tripathi et al., 2005, 2006a, 2006b). In order to obtain the possible foliage configurations based on the canopy data, a new MCMC sampling technique was developed such that a set of foliage configurations generated by the model 
approximately reconstructed the field observations of the PPFD pattern. The expected advantages of the MCMC sampling were (1) no bias correction is required as compared with the estimates underestimated by LAI-2000; (2) more informative estimations of the canopy spatial structure are obtained than those by the litterfall methods; (3) the confidence interval of the possible canopy structure can be used to evaluate uncertainties of the information that we can specify based on a given data set.

\section{Field data}

Field data were collected in an even-aged, pure stand of Japanese mountain birch Betula ermanii Cham. (17-year-old), a typical deciduous broad-leaved secondary forest in cool-temperate and sub-boreal regions (Uemura, 1993), located at Moshiri in the Uryu Experimental Forest of Hokkaido University in Hokkaido Prefecture, northern Japan (580 m above sea level; $\left.44^{\circ} 22^{\prime} \mathrm{N}, 142^{\circ} 15^{\prime} \mathrm{E}\right)$. This B. ermanii stand initiated after the scarification (Umeki, 2003; Yoshida et al., 2005) in 1984 and has been maintained as a mono-layer stand of $B$. ermanii trees after the understory removal management since 1998 (details in Takahashi et al., 2002; Tripathi et al., 2005, 2006a, 2006b). The stand density, total basal area and mean height of $B$. ermanii trees in this stand were 10,844 trees ha ${ }^{-1}, 17.1 \mathrm{~m}^{2} \mathrm{ha}^{-1}$ and $6.84 \pm 1.99 \mathrm{~m}$ 
in 2002. The canopy surface of this stand was exposed to full sunlight in almost all directions because the stand is located at the top of a flat ridge. The leaf emergence of B. ermanii trees usually begins in late May and succeeds during the growing season (Koike, 1995). Leaf fall completed by late October.

In the mid-summer, when $B$. ermanii leaves were well developed, the threedimensional light intensity distribution in the canopy was measured under diffuse light (cloudy) conditions in the daytime from July 30 to August 7, 2002. The solar radiation was measured as the photosynthetically active photon flux density (400$700 \mathrm{~nm}, \mathrm{PPFD}$ ) with a gallium arsenide phosphide photodiode (G1118, Hamamatsu Photonics, Shizuoka, Japan) calibrated against a quantum sensor (LI-190S, Li-Cor, Lincoln, NE, USA) (Nishimura et al., 1998). A photosensor array was constructed after Nishimura and Itoh (2003). In the present survey, the photodiodes were horizontally placed at intervals of $30 \mathrm{~cm}$ to a plastic plate of $1.5-\mathrm{cm}$ width, which was attached to a pole of $3 \mathrm{~m}$ length and $3 \mathrm{~cm}$ diameter. The photosensor array was inserted into B. ermanii canopy at horizontal and vertical intervals of $0.6 \mathrm{~m}$ from a canopy access tower (ca. $7.2 \mathrm{~m}$ length, $0.9 \mathrm{~m}$ width and $7.2 \mathrm{~m}$ height) for a $3 \mathrm{~m} \times 6 \mathrm{~m}$ ground area. Subsequently, PPFDs at 1452 points were measured under the canopy (Fig.1). Full sunlight over the canopy surface was also measured at a height of 9.8 m. All photodiodes were connected to a multichannel data logger (Thermodac-EF, 


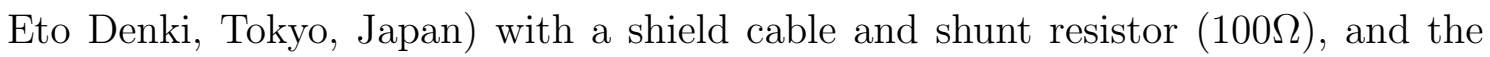
voltage values from the incident electric current were stored simultaneously. From these values, the instantaneous PPFD ( $\mu$ mol photons $\left.\mathrm{m}^{-1} \mathrm{~s}^{-1}\right)$ in the daytime for each position in the canopy is converted into the relative PPFD (R-PPFD), i.e., a normalized value by the corresponding PPFD measurement on the canopy surface. The relative PPFD was regarded as a representative light intensity in the canopy in the growing season.

As a reference value for leaf amount/density in the canopy in the growing season, the plant area index (PAI, area index including leaf, stem, and trunk) beneath the canopy was estimated with a plant canopy analyzer (LAI-2000, Li-Cor, Lincoln, NE, USA) under the diffuse light conditions in the daytime from July 31, August 4, and 6, in 2002. A measurement cycle consisted of a reference measurement and below-canopy readings. The reference measurements were conducted at the top of the canopy access tower (open sky condition, ca. $9 \mathrm{~m}$ height) at the beginning of each cycle. The below-canopy measurements at a height of $2.4 \mathrm{~m}$ were carried out at horizontal grids determined for relative PPFD (R-PPFD; 0.6-m intervals, 69 points). At each point beneath the canopy, three measurements are conducted along three direction, i.e. west, east, and south. The below-canopy measurement of north direction was not obtained to avoid the influences of the tower in the direction. 
LAI-2000 evaluated a PAI estimate at each point by referring to the combination of the reference and three below-canopy measurements. The PAI of the research plot was defined as the average over PAI estimates at 69 points. It took three days to complete the measurements. The fish-eye lens of the sensor of the instrument was covered with a view cap with a $90^{\circ}$ opening in azimuth to minimize the overlapping between three different directions of below-canopy measurements and to eliminate the influences of the operator to the measurements.

Furthermore, the litterfall amount in a growing season was measured. Four circular litter traps with $0.5 \mathrm{~m}^{2}$ surface area were set in the stand $1.3 \mathrm{~m}$ above the ground level in the $15 \mathrm{~m} \times 7.5 \mathrm{~m}$ ground area of the stand on June 13, 2002. Litterfall in the traps was collected on October 25, 2002. From the litterfall, the leaves were sorted and then dried at a laboratory temperature to achieve a constant weight. To obtain the leaf area index (LAI) of the stand, the total dry leaf mass collected per unit ground area during a growing season was multiplied by the mean annual specific leaf area (SLA, leaf area per unit dry leaf mass) over the growing season. To obtain SLA, 48 well-developed mature leaves were harvested in the canopy from June to October 2002. The projected area of each leaf was determined with LI-3100C Area Meter (Li-Cor, Lincoln, NE, USA). Then, each leaf was dried at $80^{\circ} \mathrm{C}$ and weighed.

The light responses of leaf gas exchange characteristics were measured for sun 
leaves of B. ermanii using a portable gas exchange system (LI-6400, Li-Cor, Lincoln, NE, USA) from July 29 to August 3, 2002. Five B. ermanii trees forming the canopy were selected out of all 18 trees in the PPFD measurement space (Fig.1) and a well-sunlit branch was cut from the crown surface of each tree. Immediately after cutting, the base of the stem was recut under water. Then, the shoots were sealed in plastic bags and transported to the laboratory for the measurements. We selected one fully expanded mature summer-leaf from the longest shoot of the current year for measurement (usually the fourth leaf from the shoot tip). The PPFD level on the leaf was reduced in a stepwise manner from 1600 to $0 \mu \mathrm{mol} \mathrm{m} \mathrm{m}^{-2} \mathrm{~s}^{-1}$. Blue and red LEDs (LI-6400-02B) were used as a light source for the measurements. The area-based net photosynthetic rate (net $\mathrm{CO}_{2}$ assimilation rate) and transpiration rate at each PPFD level were obtained at a constant leaf temperature of $25^{\circ} \mathrm{C}$. The $\mathrm{CO}_{2}$ concentration of the air entering the leaf chamber was maintained at 360 $\mu \mathrm{mol} \mathrm{mol}{ }^{-1}$. The leaf-to-air water vapor deficit during the measurements was around $1.0 \mathrm{kPa}$. The flow rate of the air was $500 \mu \mathrm{mol} \mathrm{s}^{-1}$.

The photosynthetic rate under the foliage surface PPFD $\left(I ; \mu \mathrm{mol}\right.$ photons $\left.\mathrm{m}^{-2} \mathrm{~s}^{-1}\right)$ is given by a non-rectangular hyperbolic function (Thornley, 1976; Thornley, 2002)

$$
A(I)=\frac{\phi I+A_{\max }-\sqrt{\left(\phi I+A_{\max }\right)^{2}-4 \phi I \theta A_{\max }}}{2 \theta}-R,
$$


where $A(I)\left(\mu \mathrm{mol} \mathrm{CO}_{2} \mathrm{~m}^{-2} \mathrm{~s}^{-1}\right)$ is the photosynthetic rate at PPFD $I ; \phi(\mu \mathrm{mol}$ $\mathrm{CO}_{2} \mu \mathrm{mol}^{-1}$ photons), quantum yield of photosynthesis; $A_{\max }$, the maximum photosynthetic rate near the saturating PPFD; $\theta$, the degree of convexity of the curve; and $R\left(\mu \mathrm{mol} \mathrm{CO}_{2} \mathrm{~m}^{-2} \mathrm{~s}^{-1}\right)$, the dark respiration rate of leaf. The transpiration rate

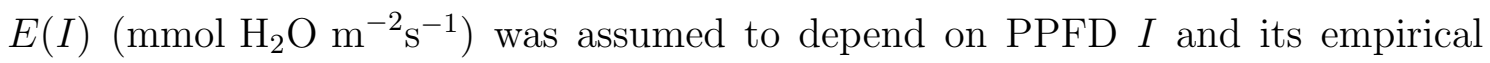
functional form was light saturated, i.e.,

$$
E(I)=a-(a-b) \exp (-c I)
$$

where $a\left(\mathrm{mmol} \mathrm{H}_{2} \mathrm{O} \mathrm{m}^{-2} \mathrm{~s}^{-1}\right)$ is the maximum transpiration rate near the saturating PPFD; $b\left(\mathrm{mmol} \mathrm{H}_{2} \mathrm{O} \mathrm{m} \mathrm{m}^{-2} \mathrm{~s}^{-1}\right)$, the transpiration rate in the dark; and $c$, the coefficient of $I$. All the parameter estimations for the photosynthetic and transpiration rates at a single foliage level were performed by using the nonlinear least-squares method with the nls() function of $\mathrm{R}$ ( $\mathrm{R}$ Development Core Team, 2006) based on the mean of the measurements of the five leaves.

\section{Canopy Modeling}

In order to generate a set of "likely" spatial distributions of foliage locations and directions (foliage configurations) of the focal canopy based on the three-dimensional measurement of PPFD, we developed a method that consists of two major compo- 
nents: PPFD calculator and Markov chain Monte Carlo (MCMC) sampler (Gilks et al., 1996). The PPFD calculator predicts the three-dimensional distribution of the R-PPFD (PPFD pattern) under a given foliage configuration. The MCMC sampler drives the stochastic transitions of the foliage configurations by the MetropolisHastings algorithm while evaluating the goodness of fit (likelihood) of the estimated PPFD pattern to the data. In this section, we firstly describe the details of the Gibbs foliage canopy, which is a new model developed in the current study. We then define a conventional canopy model, called the horizontal foliage canopy.

\subsection{PPFD calculator}

To conduct the MCMC sampling of the possible foliage configuration space, we chose one of the simplest algorithms to evaluate the PPFD pattern. To reduce computing time, such an algorithm employs some simplifications such as restricting the total number of directions of incident light (hereafter "light directions") to five.

The light directions depend on the coordinate system that is defined for the light measurement in the canopy described in the previous section (Fig.1). The three-dimensional space defined in Fig.1 is referred to as "light simulation space" to evaluate PPFD. This is divided into a set of "boxes" of a fixed size $(\Delta x, \Delta y, \Delta z)$ (refer to Fig.1b). A box has a photosensor at the center of its base plane whose 
location vector is given as $b=(x, y, z)$. The notation "box $b$ " denotes a box that has its photosensor at location vector $b$. The R-PPFD at the photosensor in box $b$ is evaluated as the sum of R-PPFD of all the incident lights from the upper boxes of box $b$ (Fig.2). An upper box of box $b$ is denoted as box $b+\delta$, where $\delta$ is an element of the set $\{\delta\}$ of light direction vectors. Since the common size of all the boxes is $(\Delta x, \Delta y, \Delta z)$, the five direction vectors from the focal box $b$ to the upper boxes are always,

$$
\begin{aligned}
& \delta_{1}=(0,0,+\Delta z), \\
& \delta_{2}=(-\Delta x, 0,+\Delta z), \delta_{3}=(0,-\Delta y,+\Delta z), \\
& \delta_{4}=(+\Delta x, 0,+\Delta z), \delta_{5}=(0,+\Delta y,+\Delta z),
\end{aligned}
$$

as shown in Fig.2. The pairs $\left\{\delta_{2}, \delta_{4}\right\}$ and $\left\{\delta_{3}, \delta_{5}\right\}$ are referred to as the pairs of opposite directions that are used in the correction of boundary effects.

The set $\{\delta\}$ of box $b$ is modified if the box is located at the edge of the light simulation space for the correction of boundary effects. The boundary conditions for "walls" and "ceiling" are different in the light simulation. Since we employ the reflecting boundary condition for all walls (upper/lower x-z and y-z planes), the vector $\delta_{j}$ of the photon input from the outside of the space is replaced by the vector of the counterpart of the pairs of directions. For example, if the box at location $b+\delta_{3}$ is outside of the space, the set $\{\delta\}$ of the focal box $b$ is changed as $\left\{\delta_{1}, \delta_{2}, \delta_{5}, \delta_{4}, \delta_{5}\right\}$ in which $\delta_{3}$ is replaced by its counterpart $\delta_{5}$. By the double counting of $\delta_{5}$, in the 
example, the R-PPFD in box $b$ is adjusted under the fixed boundary condition. The boundary condition for ceiling (upper $\mathrm{x}-\mathrm{y}$ plane) is described later.

The partial light from direction $\delta$ is assumed to be the set of parallel rays from direction $\delta$. In order to divide and handle the rays from direction $\delta$, a light corridor $C_{b, \delta}$ (Fig.2) is defined as the set of all "light ray segments" that penetrate the base planes of the boxes $b$ and $b+\delta$. As shown in Fig.2 and Fig.3, the shape of $C_{b, \delta}$ is the parallelogram prism that connects the base planes of boxed $b$ and $b+\delta$. The partial R-PPFD from direction $\delta$ on the base plane of box $b$ is assumed to be uniform. Hence, the averaged R-PPFD $I_{b, \delta}$ is represented by the R-PPFD evaluated at the photosensor of box $b$ (Fig.1b).

The light interceptors in the light corridor $C_{b, \delta}$ are foliage units and non-foliage objects. A foliage unit represents a discrete aggregation of leaves developed on tree branches. In the light simulation space, a foliage unit is simplified as a disk with an area $A_{f}$ without thickness, which is common for all foliage units. Both the location of the disk center and the unit normal vector $\delta_{f}$ are also the characteristics of a foliage unit. The light extinction rate in light corridor $C_{b, \delta}$ is affected by the inner product of the normal vector of the foliage unit and the direction $\delta$ of $C_{b, \delta}$. The non-foliage objects such as trunk and branches are not treated explicitly in the model, but they reduce $I_{b, \delta}$ at a constant rate per unit height (specified later). 
The R-PPFD estimates at all photosensors in the space were predicted successively in order of the height of box location from top to bottom, because the changes in the R-PPFD estimates in the upper boxes affect the lower boxes but not viceversa. As the first step, the photon input from each direction $\delta$ is evaluated under a given foliage configuration $k$. A configuration $k$ is defined as a set of given foliage units of which characteristics are specified. The (partial) photon input $I_{b, \delta}^{(k)}$ from the direction $\delta$ at the photosensor of box $b$ results in the product of the output of photons $O_{b+\delta, \delta}^{(k)}$ (Fig.3a) from box $b+\delta$ and the fraction of light transmittance in the light corridor $C_{b, \delta}$,

$$
I_{b, \delta}^{(k)}=(1-d) O_{b+\delta, \delta}^{(k)} \prod_{f \in C_{b, \delta}}\left(1-\frac{(1-a) A_{f} \delta_{f} \cdot \delta}{A_{b} \delta_{b} \cdot \delta}\right),
$$

where $d$ is the constant of the light extinction rate by non-foliage objects $(0 \leq d \leq 1)$ that is independent of $\delta$; $f \in C_{b, \delta}$ denotes a foliage unit $f$ that is located in the light corridor $C_{b, \delta} ; \delta_{*} \cdot \delta$ denotes the inner product of vectors $\delta_{*}$ and $\delta$; $a$ is the light absorption rate by a foliage unit $(0<a<1)$; and $A_{b}$ and $\delta_{b}$ are the area $(=\Delta x \times \Delta y)$ and the unit normal vector (Fig. $3 \mathrm{~b}$ ) of the base plane of box $b$, respectively. The above is equivalent to assuming that the position of the center of each foliage unit projected to a plane normal to $\delta$ takes a random position on the plane irrespective of the positions of other foliage units. The light interception model expressed by the equation is almost the same as the Beer-Lambert's law in the Monsi-Saeki model 
(Monsi and Saeki, 1953, 2005). Suppose $Q_{\delta}$ is a plane whose normal vector is $\delta$ and $f \in C_{b, \delta}$ is a foliage unit whose center is located on $Q_{\delta}$. On the part of a plane $Q_{\delta}$ that is sectioned by the light corridor $C_{b, \delta}$, the light extinction rate by a single foliage unit is calculated by the ratio of the projection area of $A_{f}$ onto $Q_{\delta}$ and that of the base area of the box $b\left(A_{b}\right)$ onto $Q_{\delta}$.

Since the unit normal vectors of all the photosensors are equal to $(0,0,1)$ (i.e., the direction vector of the photosensor is equal to the unit normal vector $\delta_{b}$ of box $b)$, the R-PPFD at the sensor in box $b$ is evaluated as the weighted average of all the photon inputs $I_{b, \delta}^{(k)}$ from direction $\delta$,

$$
I_{b}^{(k)}=\frac{\sum_{\delta \in\{\delta\}} I_{b, \delta}^{(k)} \delta \cdot \delta_{b}|\delta|^{-1}}{\sum_{\delta \in\{\delta\}} \delta \cdot \delta_{b}|\delta|^{-1}},
$$

where the weight of direction $\delta$ is proportional to the inner product of $\delta$ and $\delta_{b}$.

The photon output $O_{b, \delta}^{(k)}$ (Fig.3a) from direction $\delta$ of box $b$ was defined as a mixture of the photon input $I_{b, \delta}^{(k)}$ from direction $\delta$ and the averaged light incident on the base of box $b$,

$$
O_{b, \delta}^{(k)}=(1-m) I_{b, \delta}^{(k)}+m I_{b}^{(k)}
$$

where $m$ is the constant for the light mixture $(0 \leq m \leq 1)$. The light mixture parameter represents two processes of light radiation: the degree of diffused reflection in the canopy and the variance in light direction distribution that is neglected by 
the approximation of parallel rays.

The "ceiling" (upper x-y plane) of the light simulation space has the fixed boundary condition. Let us assume that a box $b$ located at the top of a box column at a given $(x, y)$ has an observed R-PPFD measurement $I_{b}^{(o)}$. Since the light distribution on the celestial sphere is uniform (i.e. perfectly cloudy condition), the (partial) output of photons from direction $\delta$ from a dummy box is proportional to $\delta \cdot \delta_{b}|\delta|^{-1}$, where $\delta_{b}$ is the unit normal vector $(0,0,1)$. Suppose box $b$ is the focal dummy box, and the photon output $O_{b, \delta}$ from direction $\delta$ of box $b$ is defined as,

$$
O_{b, \delta}=I_{b}^{(o)} \frac{\delta \cdot \delta_{b}|\delta|^{-1}}{\sum_{\delta^{\prime} \in\{\delta\}} \delta^{\prime} \cdot \delta_{b}\left|\delta^{\prime}\right|^{-1}},
$$

where $\{\delta\}=\left\{\delta_{1}, \delta_{2}, \cdots, \delta_{5}\right\}$.

\subsection{MCMC sampler}

The likelihood of a foliage configuration $k$ under the observed light data in the Moshiri plot was defined for the MCMC sampling of the foliage configuration in the canopy. The goodness of fit of the predicted R-PPFD $I_{b}^{(k)}$ to the observed R-PPFD $I_{b}^{(o)}$ is evaluated at each box $b$ under foliage configuration $k$. We assumed $I_{b}^{(o)}$ to be a random number following the normal distribution with mean $I_{b}^{(k)}$ and variance $\sigma^{2}$; 
the $\log \operatorname{likelihood} L^{(k)}$ over all light measurements was then defined as,

$$
L^{(k)}=\sum_{b \in\{b\}}\left[-\frac{\left(I_{b}^{(o)}-I_{b}^{(k)}\right)^{2}}{2 \sigma^{2}}-\frac{\log \left(2 \pi \sigma^{2}\right)}{2}\right],
$$

where $\{b\}$ is the set of all boxes in the light simulation space. Therefore, we assumed that the probability that a foliage configuration $k$ is observed is proportional to $\exp \left(L^{(k)}\right) / \sum_{k^{\prime}} \exp \left(L^{\left(k^{\prime}\right)}\right)$ where the denominator of the probability is called the normalized constant (Liu, 2001), the sum of likelihoods for all possible foliage configuration. The probability density of all possible foliage configurations defined above is identical to the definition of the Gibbs distribution (or Boltzmann distribution). During the MCMC sampling, samples are drawn from the Gibbs distribution; the sampled foliage configuration, whose likelihood is defined as above, is referred to as the "Gibbs foliage canopy" in the current study.

Starting from a vacant space (i.e., no foliage unit), the foliage configuration was updated at each MCMC step. An MCMC step includes two stochastic procedures of "foliage manipulations", or manipulations of foliage configuration: foliage increment and decrement (Fig.4). In foliage increment, a foliage unit was added at a random location in a randomly selected box. The unit normal vector of the newly added foliage unit was randomly selected such that the azimuth follows the uniform distribution $[0,2 \pi)$ and the zenith followed the uniform distribution $[0,0.5 \pi)$. Note that the sampled vector is not uniformly spherically distributed, but rather so that there 
is a higher density near zenith. For leaf normal vectors, this means higher probability for leaf orientations close to horizontal. In foliage decrement, a randomly selected foliage unit in a randomly chosen box was eliminated, if the box included at least one foliage unit; otherwise no action was taken. The increment or decrement of a foliage unit $f$ affects not only the R-PPFD at box $b$ including $f$, but also all the boxes located adjacent to and below box $b$ by the transport of light.

The stochastic transition of the foliage configuration is determined by the MetropolisHastings algorithm (Liu, 2001) on the basis of which the increment and decrement foliage procedures are performed. Suppose a foliage configuration $k^{\prime}$ can be changed by some foliage manipulation to a configuration $k$. In the Metropolis-Hastings algorithm, the transition from foliage configuration $k$ to $k^{\prime}$ is made at the probability of the minimum of unity and the likelihood ratio of the configuration $k^{\prime}-k$, i.e., $\min \left(1, \exp \left(L^{\left(k^{\prime}\right)}-L^{(k)}\right)\right)$. Therefore, the foliage configuration is changed from $k$ to $k^{\prime}$ if $L^{\left(k^{\prime}\right)}$ is greater than $L^{(k)}$, and if $L^{\left(k^{\prime}\right)}$ is smaller than $L^{(k)}$, the probability of the transition increases as $L^{\left(k^{\prime}\right)}$ is closer to $L^{(k)}$. In the case where the new foliage configuration $k^{\prime}$ is rejected, the foliage configuration retains the status $k$ before the foliage manipulation. The manner of sampling corresponding to a Bayesian inference by using a random walk Metropolis sampler (Liu, 2001) under non-informative prior distribution for the foliage configuration. 
The stochastic change in the number of foliage units at each MCMC step is similar to a random walk bound from zero to infinity, because there is no explicit limitation to the number of foliage units in the model. Practically, by using the MCMC sampler, a balance between the increment and decrement of foliage units will be maintained around some appropriate foliage density such that the R-PPFD patterns when the foliage configurations are similar to the Moshiri R-PPFD data. This will occur if the Markov chain of the foliage configuration converges to the stationary distribution in which the algorithm can obtain random samples from the Gibbs distribution defined earlier in this section.

In order to improve the MCMC sampling efficiency, we performed the parallel tempering of MCMC (Liu, 2001) in which eight independent MCMCs (replica chains) were updated and swap the foliage configurations at each MCMC step. In order to represent the degree of strictness in the applying of Metropolis-Hastings rule in MCMC, we introduced a "temperature" parameter. The main feature of the parallel tempering is that the probability of the transition of foliage configuration for each chains is modified by the temperature parameter as follows:

$$
\min \left(1, \exp \left(\frac{L^{\left(k^{\prime}\right)}-L^{(k)}}{T}\right)\right)
$$

where $T$ is a temperature in the set of temperature gradient $\left\{T_{1}, T_{2}, \cdots, T_{8}\right\}\left(T_{1}<\right.$ $\left.T_{2}<\cdots<T_{8}\right)$. At the lowest temperature $T_{1}=1$, the transition probability of the 
foliage configuration is evaluated as the same to be the ordinal Metropolis-Hastings sampling in MCMC described above, while the probability increases with temperature. At each MCMC step, the foliage configurations were swapped between the chains of temperature $T_{i}$ and $T_{i+1}$ at the Metropolis-Hastings probability modified by the difference between the inverse of temperatures $T_{i}$ and $T_{i+1}$ (Liu, 2001),

$$
\min \left(1, \exp \left[\left(\frac{1}{T_{i}}-\frac{1}{T_{i+1}}\right)\left(L_{T_{i}}^{(k)}-L_{T_{i+1}}^{\left(k^{\prime}\right)}\right)\right]\right)
$$

By changing the temperature that a series of foliage configuration experiences, the set of independent foliage configurations can easily diverge from the local maximum of the Gibbs distribution as compared to the MCMC sampling at a single constant temperature, $T=1$. The foliage configurations are sampled only from the chain at the lowest temperature $T_{1}$.

The software for the PPFD calculation and the MCMC sampling is written in Perl and $\mathrm{C++}$, the source code of which is available at http://hosho.ees.hokudai. ac.jp/ kubo/r/moshiri/archive/. The MCMC sampling size was 30 with a $10 \mathrm{~K}$ step interval after 1010K burn-in MCMC steps. The temperature settings for the parallel tempering were as follows: the lowest temperature $T_{1}$ was set to one, and the difference between $1 / T_{i}$ and $1 / T_{i+1}$ was fixed at 0.005 . Since it was difficult to simultaneously obtain foliage configurations and parameter estimates in the current study, all the model parameters were arbitrarily fixed as follows: light absorption of 
foliage, $a=0.90$; area of box base plane $A_{b}=30 \times 60\left(\mathrm{~cm}^{2}\right)$; area of foliage disk, $A_{f}$ $=5^{2} \pi\left(\mathrm{cm}^{2}\right)$; light absorption of box, $d=0.05$; light mixture, $m=0.5$; and variance of $I, \sigma^{2}=100$. In the estimation of $I$, the predicted R-PPFDs are renormalized to a range between 0 and $1400 \mu \mathrm{mol}$ photons $\mathrm{m}^{-2} \mathrm{~s}^{-1}$, where $1400 \mu \mathrm{mol}$ photons $\mathrm{m}^{-2} \mathrm{~s}^{-1}$ is the approximated value of the maximum PPFD in the Moshiri study plot.

\subsection{Horizontal foliage canopy}

A conventional canopy model (referred to as the horizontal foliage canopy) is introduced to compare the results with those for the Gibbs foliage canopy. The model is deterministic and all the unit normal vectors of the foliage units are fixed as $(0,0,1)$, i.e. horizontal foliage units. As in the classical Monsi-Saeki model (Monsi and Saeki, 1953, 2005), the fraction of intercepted light in a box is proportional to the local LAI in the box if all foliage units are horizontal. In the horizontal foliage canopy, each box of the horizontal foliage canopy has a single foliage unit of variable local LAI in the box just above the photosensor. The estimate of local LAI $A_{f}$ in box $b$ is derived as $A_{f}=A_{b} \log \left(I_{b^{\prime}}^{(o)} / I_{b}^{(o)}\right)$, where $A_{b}$ is the area of the base plane of box $b$; box $b^{\prime}$ is located immediately above box $b$; and $I_{b^{\prime}}^{(o)}$ and $I_{b}^{(o)}$ are the observed R-PPFD at the photosensors of box $b^{\prime}$ and $b$, respectively. The PPFD pattern for the horizontal foliage canopy was further estimated by the PPFD calculator which 
was also used for the Gibbs foliage model.

\subsection{Canopy production and evapotranspiration}

The set of foliage configurations obtained by the horizontal and Gibbs foliage canopy models were evaluated by their stand canopy production and evapotranspiration with referring the estimated rates per unit area, i.e., $A(I)\left(\mu \mathrm{mol} \mathrm{CO}_{2} \mathrm{~m}^{-2} \mathrm{~s}^{-1}\right)$ for canopy production in Eq.(1) and $E(I)\left(\right.$ mmol $\left.\mathrm{H}_{2} \mathrm{O} \mathrm{m}^{-2} \mathrm{~s}^{-1}\right)$ for evapotranspiration in Eq.(2). In the prediction under Gibbs canopy model, both of these rates per stand canopy were defined as a function of the sum of light interceptions at every foliage unit (used in the PPFD calculator, a disk of $5 \mathrm{~cm}$ radius) from all directions, i.e., $\sum_{f} \sum_{\delta} R\left(I_{f, \delta}\right) A_{f} \delta_{f} \cdot \delta$ where $R(I)$ is either $A(I)$ or $E(I) ; f$ and $\delta$ denote a foliage unit and a light direction vector, respectively; $I_{f, \delta}\left(\mu \mathrm{mol}\right.$ photons $\left.\mathrm{m}^{-2} \mathrm{~s}^{-1}\right)$ is the estimated total PPFD at $f$ with considering the effects of crossing angle between $f$ and $\delta ; A_{f} \delta_{f} \cdot \delta=2.5 \times 10^{-3} \pi \delta_{f} \cdot \delta\left(\mathrm{m}^{2}\right)$ is the projected area of foliage unit $f$ to direction $\delta$. The partial PPFD $I_{f, \delta}$ was evaluated by the three dimensional PPFD calculator. In the horizontal canopy model, the rates for the stand canopy were evaluated as $\sum_{b} R\left(I_{b}\right) A_{b}$ where $b$ denotes an unit box; $I_{b}$ and $A_{b}$ is the estimated PPFD and the estimated LAI of horizontal foliage at $b$ described above, respectively. In both case, the thickness of foliage unit was assumed to be zero. 


\section{Results}

Since the foliage configuration based on the horizontal foliage canopy (HFC) model is deterministic in this model, the local LAI at a given location corresponds to the amount of light extinction at a particular location (Fig.5a) in which the spatial distribution of disk sizes expresses the heterogeneity of the degrees of light interceptions in the observed R-PPFD data. On the other hand, the foliage configuration based on the Gibbs foliage canopy (GFC) model is stochastic. Therefore, the foliage configuration at 1300K MCMC steps is shown in Fig.6a as an example. The difference between the observed and predicted PPFD at each photosensor is smaller in the GFC model (Fig.6b) than in the HFC model (Fig.5b).

By using the foliage configuration shown in Fig.6a which includes foliage units obtained from 12751 foliage units, a snapshot of the vertical profile and zenith angle distribution of the foliage units were obtained. The vertical distribution of the foliage units (Fig.7a) indicates that the mode of the distribution was in a range of $z=450-550 \mathrm{~cm}$ height. A histogram of the zenith angles of the normal vectors of the foliage units (the foliage normal vectors) which approach uniform distribution is shown in Fig.7b. A foliage unit is horizontal if the zenith angle of its normal vector is zero, whereas it becomes more vertical as the zenith angle increases. 
The increment of LAI in the GFC model was almost saturated after 800-1000K MCMC steps (Fig.8a). The mean and SD of the posterior distribution of LAI (Fig.8b) were 4.54 and 0.044, respectively, based on 30 LAI samples (open circles in Fig.8a) sampled with a 10K step interval after 1010K MCMC steps. The computation time for $1300 \mathrm{~K}$ MCMC steps was about 520-530 minutes by using a Pentium 4 $(2.4 \mathrm{GHz})$ personal computer.

The parameters for photosynthetic and transpiration rates at the foliage level were estimated based on the mean of measurements of five leaves shown in (Fig.9) as follows: $\hat{A}_{\max }=17.3, \hat{\phi}=6.80 \times 10^{-2}, \hat{\theta}=5.68 \times 10^{-1}$, and $\hat{R}=2.23$ for the foliage photosynthetic rate given by Eq.1; and $\hat{a}=3.44, \hat{b}=1.13$, and $\hat{c}=1.75 \times 10^{-3}$ for the foliage transpiration rate given by Eq.2.

The LAI estimate obtained by using LAI-2000 was 3.43. The estimate of mean leaf number in a litterfall trap was 1240.5, since the mean sample dry weight and total dry weight of leaves (mean number was 545.8) in a litterfall trap were 67.8 (g) and $154.1(\mathrm{~g})$, respectively. Based on the mean area of 48 sample leaves $\left(22.4 \mathrm{~cm}^{2}\right)$ and the area of the litterfall traps $\left(5000 \mathrm{~cm}^{2}\right)$, the estimate of LAI was 5.56, i.e. $1240.5 \times 22.4 / 5000$ (Table 1$).$ The estimates of both the canopy production and evapotranspiration of GFC are greater than those of HFC (Table 1). 


\section{Discussion}

The most interesting result obtained by the Gibbs foliage canopy (GFC) model is that the posterior distribution of the estimated LAI $\left(\mathrm{LAI}_{\mathrm{G}}\right)$ lies in a narrow range (Table 1), which is generated by the parallel tempered MCMC in which eight independent Markov chains of canopy foliage configurations were in different "temperature" histories. The narrow range of $\mathrm{LAI}_{\mathrm{G}}$ suggests that our field measurements of the PPFD pattern contains adequate information to specify the possible set of canopy structures in terms of the LAI evaluated by GFC model. Despite the lack of prior information on LAI, the posterior distribution of $\mathrm{LAI}_{\mathrm{G}}$ (approximately 4.5) appears to be appropriate because Tadaki (1970) reported that the LAI of a secondary growth Betula ermanii stand, which was about 30 years old, was 4.2 ; this was estimated by using the destructive method of the stratified clip technique in the subalpine zone of central Japan. Sakai et al. (2006) reported the LAI of birch stand consisting of Betula platyphylla and B. ermanii was $4.45 \pm 1.96$; this was estimated based on the averaged light transmission in 100 sub-plots $(10 \mathrm{~m} \times 10 \mathrm{~m})$ in a 1 ha site of a cool-temperature deciduous broadleaf forest in central Japan.

The $\mathrm{LAI}_{\mathrm{G}}$ of the B. ermanii stand in Moshiri, however, was slightly greater than that of Tadaki (1970). This is probably attributable to the fact that $\mathrm{LAI}_{\mathrm{G}}$ was fairly 
close to the plant area index (PAI) as compared to LAI because some foliage units in the GFC model could intercept PPFD on behalf of trunks and large branches of $B$. ermanii trees in the Moshiri stand. This conjecture is consistent with the observation that the GFC has several foliage units below the canopy (Fig.7a), as in Fig.6a. In regard to this matter, we would point that the model of light extinction could be too simple as follows: (1) a single parameter $d$ represents the light extinction rate by non-foliage objects; (2) light only propagates from the nearest 5 boxes above in the light propagate model; and (3) the light measurements were done with flat cosine response PPFD sensors without taking into account the penetration angle of light.

The information obtainable from field measurements depends on the data structure and the statistical model that is applied to the data. The vertical distribution of foliage units included more than 1000 foliage units below a height of $200 \mathrm{~cm}$. These foliage units at lower heights probably act as a replacement for light interception by trunks because there are no trees that maintain a canopy at that height (Tadaki, 1970). The posterior distribution of the vertical location of foliage units could be changed by improving the modeling of trunks. Another possible failure is the non-informative prior distribution of foliage angle distribution (Fig.7b). The nearly uniform distribution of the zenith angles of the normal vectors of the foliage units indicates that the angle of the foliage unit is random. This suggests that it is 
difficult to estimate leaf angles only by using the three-dimensional distribution of PPFD with no prior information of foliage angle distribution.

Although the estimation technique in the current study requires certain improvements, the range of $\mathrm{LAI}_{\mathrm{G}}$ appears to be reasonable when compared with the LAI estimates obtained by applying other methods to the same PPFD distribution data (Table 1). The $\mathrm{LAI}_{\mathrm{G}}$ was greater than the estimates of the horizontal foliage canopy (HFC) model and LAI-2000, which are theoretically underestimated because of the assumptions in these models. The difference between the estimates from LAI-2000 and GFC could not be explained by the assumption of random foliage angle, because, in GFC, the distribution of the angles was nearly uniform (Fig.7b). Therefore, the clumping effects of foliage units in the three dimensional space may affect to the result. On the other hand, $\mathrm{LAI}_{\mathrm{G}}$ was smaller than the estimate of LAI based on the litterfall trap data. The LAI estimate based on the litterfall trap data should be overestimated because the litterfall traps included the leaves from the beginning to the end of a growing season. Since $B$. ermanii exhibits successive leaf emergence, it is natural that the total number of leaves in a litterfall trap must be greater than the instantaneous number.

From the evaluations of the canopy production and evapotranspiration rates (Table 1), we conclude that the relationships between LAI (PAI), canopy production 
and evapotranspiration is not very simple because they depend on the models of the foliage configuration and the nonlinear functional forms of the leaf responses of photosynthesis and transpiration to PPFD (Fig.9). The relationship between LAI, canopy production and evapotranspiration indicates that the LAI estimate of GFC is 2.3 fold greater than that of HFC; however, both the canopy production and evapotranspiration of GFC are not proportional to the increment in LAI. One possible reason is that the functional forms of gas exchange are nonlinear to the PPFD. The leaf angle distribution within the canopy may have some effects on the PPFD distribution, as shown in Utsugi (1999). A foliage unit contributes to the increment of LAI but not to the canopy gas exchange, especially if the foliage unit is nearly-upright. As regard this point, the production of the foliage unit of nearly-upright can be underestimate, since there is some light coming from off-zenith angles so that even a vertically orientated leaf would photosynthesize in natural illumination conditions.

Future improvements in modeling the complexity of the canopy would be realized by the Bayesian inference for the canopy parameters that were all fixed in the current study. The Bayesian inference can be carried out simultaneously with the MCMC sampling of the canopy foliage configuration. A heterogeneous distribution of nonfoliage objects can be obtained by introducing the estimation of the light extinction rate $d$ by non-foliage objects while considering the spatial correlation (e.g. Clark and 
Gelfand, 2006) and a prior distribution expressing the probability of foliage existence depending on PPFD. The prior distribution of the zenith angle of the normal vector of foliage units depending on PPFD may generate a more valid posterior distribution of the angle such that it is more similar to the observed distribution. The current method can be improved by the advanced modeling of the PPFD pattern and canopy structure. If we are able to obtain the Lidar data of the three-dimensional forest canopy more easily (Riaño et al., 2004), more appropriate prior distributions for the canopy structure can be obtained. Another possible data set to apply the MCMC canopy sampling may be the ground-level light measurements on grid points in forest. Our method may have a potential to estimate both the vertical and horizontal structure of canopy from the two dimensional data with referring some additional data set such as on tree locations and canopy architecture. It is possible that the coupling of the estimation and functional-structural tree simulators (Roux et al., 2001) would provide more informative prior distributions for the Bayesian modeling of the canopy structure based on the physiological constraints of plants such as light availability and water balance (e.g. Kubo and Kohyama, 2005)

In the current study, MCMC sampling was conducted only for three-dimensional canopy structures because we intended to demonstrate the feasibility of the technique for the data that were spatially structured and categorized as broad-sense 
remote sensing data. In such data, the detailed status of elementary objects (e.g. location of foliage) in the photosensor range cannot be directly observed, but affects the measurements (e.g., PPFD at photosensors). The current study demonstrates the feasibility of MCMC techniques that can generate a set of possible structures of unobservable objects based on the data obtained by some indirect (or remotesensing) methods but with higher resolution, which is a typical data set in the modern forest ecology because of the improvements in measurement methods.

\section{Acknowledgments}

The staff and students of the Uryu Experimental Forest and Faculty of Agriculture, Hokkaido University, supported and assisted the field management and investigation. The members of the Institute of Low Temperature Science (ILTS), Hokkaido University, extended their support and encouragement throughout the study. We thank Dr. Yukito Iba for his helpful discussion on the modeling. We also thank two anonymous reviewers for helpful criticism. This work is part of the Joint Research Program of ILTS and Core Research for Evolutional Science and Technology (CREST, Japan Science and Technology Agency). This work was also supported by Grants-in-Aid for Scientific Research from the Ministry of Education, Science and Culture of Japan (No.15770006 and 18657012). 


\section{References}

Cescatti, A., 1997a. Modelling the radiative transfer in discontinuous canopies of asymmetric crowns. I. Model structure and algorithms. Ecological Modelling 101, $263-274$.

Cescatti, A., 1997b. Modelling the radiative transfer in discontinuous canopies of asymmetric crowns. II. model testing and application in a norway spruce stand. Ecological Modelling 101, 275-284.

Clark, J. S., Gelfand, A. E., 2006. Hierarchical modelling for the environmental sciences. Oxford University Press, Oxford.

Cutini, A., Matteucci, G., Mugnozza, G. S., 1998. Estimation of leaf area index with the Li-Cor LAI 2000 in deciduous forests. Forest Ecology and Management 105, $55-65$.

Dufrêne, E., Bréda, N., 1995. Estimation of deciduous forest leaf area index using direct and indirect methods. Oecologia 104, 156-162.

Fukushima, Y., Hiura, T., Tanabe, S., 1998. Accuracy of the MacArthur-Horn method for estimating a foliage profile. Agricultural and Forest Meteorology 92, $203-210$.

Gilks, W. R., Richardson, S., Spieglhalter, D. J., 1996. Markov chain Monte Carlo in practice. Chapman and Hall/CRC, London. 
Giuliani, R., Magnanini, E., Nerozzi, F., Muzzi, E., Sinoquet, H., 2005. Canopy probabilistic reconstruction inferred from monte carlo point-intercept leaf sampling. Agricultural and Forest Meteorology 128, 17-32.

Gower, S. T., Norman, J. M., 1991. Rapid estimation of leaf area index in conifer and broad-leaf plantations. Ecology 72, 1896-1900.

Ishii, H. T., Tanabe, S., Hiura, T., 2004. Exploring the relationships among canopy structure, stand productivity and biodiversity of temperate forest ecosystems. Forest Science 50, 342-355.

Jonckheere, I., Fleck, S., Nackaerts, K., Muys, B., Coppin, P., Weiss, M., Baret, F., 2004. Review of methods for in situ leaf area index determination Part I. Theories, sensors and hemispherical photography. Agricultural and Froest Meteorology 121, $19-35$.

Kira, T., Shinozaki, K., Hozumi, K., 1969. Structure of forest canopies as related to their primary production. Plant and Cell Physiology 10, 129-142.

Knyazikhin, Y., Mießen, G., Panfyorov, O., Gravenhorst, G., 1997. Small-scale study of three-dimensional distribution of photosynthetically active radiation in forest. Agricultural and Forest Meteorology 88, 215-239.

Koike, T., 1995. Physiological ecology of the growth characteristics of Japanese mountain birch in Northern Japan: a comparison with Japanese white birch. In: 
Box, E., Peet, R., Masuzawa, T., Yamada, I., Fujisawa, K., Maycock, P. (Eds.), Vegetation Science in Forestory. Kluwer Academic Publishers, Dordrecht, pp. 409422.

Kubo, T., Kohyama, T., 2005. Abies population dynamics simulated using a functional-structural tree model. Ecological Research 20, 255-269.

Liu, J. S., 2001. Monte Carlo strategies in scientific computing. Springer, New York. Monsi, M., Saeki, T., 1953. Über den Lichtfaktor in den Pflanzengesellschaften und seine Bedeutung für die Stoff-produktion. Japanese Journal of Botany 14, 22-52.

Monsi, M., Saeki, T., 2005. On the factor light in plant communities and its importance for matter production (an english translation of Monsi and Saeki (1953)). Annals of Botany 95, 549-567.

Muraoka, H., Koizumi, H., 2005. Photosynthetic and structural characteristics of canopy and shrub trees in a cool-temperate deciduous broadleaved forest: Implication to the ecosystem carbon gain. Agricultural and Forest Meteorology 134, $39-59$.

Muraoka, H., Koizumi, H., Pearcy, R. W., 2003. Leaf display and photosynthesis of tree seedlings in a cool-temperate deciduous broadleaf forest understorey. Oecologia $135,500-509$.

Nilson, T., 1999. Inversion of gap frequency data in forest stands. Agricultural and 
Forest Meteorology 98-99, 437-448.

Nishimura, S., Itoh, K., 2003. Spatial heterogeneity and diurnal course of photon flux density on paddy field water surface under rice plant canopy. Weed Biology and Management 3, 105-110.

Nishimura, S., Koizumi, H., Tang, Y., 1998. Spatial and temporal variation in photon flux density on rice (Oryza sativa L.) leaf surface. Plant Production Science 1, 3036.

Ogle, K., Wolpert, R. L., Reynolds, J. F., 2004. Reconstructing plant root area and water uptake profiles. Ecology 85, 1967-1978.

Pearcy, R. W., Yang, W., 1996. A three-dimensional crown architecture model for assesment of light capture and carbon gain by understory plant. Oecologia 108, $1-12$.

R Development Core Team, 2006. R: A Language and Environment for Statistical Computing. Vienna, Austria.

Riaño, D., Valladares, F., Condés, S., Chuvieco, E., 2004. Estimation of leaf area index and covered ground from airbone laser scanner (Lider) in two contrasting forests. Agricultural and Forest Meteorology 124, 269-275.

Röhrig, M., Stützel, H., Alt, C., 1999. A three-dimensional approach to modeling light interception in heterogeneous canopies. Agronomy Journal 91, 1024-1032. 
Roux, X. L., Lacointe, A., Escobar-Gutiérrez, A., Dizès, S. L., 2001. Carbon-based models of individual tree growth: A critical appraisal. Annals of Forest Science $58,469-506$.

Running, S. W., Coughlan, J. C., 1988. A general model of forest ecosystem processes for regional applications I. Hydrologic balance, canopy gas exchange and primary production processes. Ecological Modelling 42, 125-154.

Sakai, T., Akiyama, T., Saigusa, N., Yamamoto, S., Yasuoka, Y., 2006. The contribution of gross primary production of understory dwarf bamboo, Sasa senanensis, in a cool-temperate deciduous broadleaved forest in central Japan. Forest Ecology and Management 236, 259-267.

Sumida, A., 1993. Growth of tree species in a broadleaved secondary forest as related to the light environment of crowns. Journal of Japanese Forestry Society 75, 278286.

Sumida, A., 1995. Three-dimensional structure of a mixed broad-leaved forest in Japan. Vegetatio (Plant Ecology) 119, 67-80.

Tadaki, Y., 1970. Studies on the production structure of forest. XVII. Vertical change of specific leaf area in forest canopy. Journal of the Japanese Forestry Society 52, $263-268$.

Takahashi, K., Uemura, S., Hara, T., 2002. Effect of understory dwarf bamboo on 
seasonal changes in soil temperature in a Betula ermanii forest, northern Japan. Eurasian Journal of Forest Research 5, 49-53.

Takahashi, K., Uemura, S., Suzuki, J.-I., Hara, T., 2003. Effects of understory dwarf bamboo on soil water and the growth of overstory trees in a dense secondary Betula ermanii forest, northern Japan. Ecological Research 18, 767-774.

Thornley, J. H. M., 1976. Mathematical models in plant physiology. Academic Press, London.

Thornley, J. H. M., 2002. Instantaneous canopy photosynthesis: analytical expressions for sun and shade leaves based on exponential light decay down the canopy and an acclimated non-rectangular hyperbola for leaf photosynthesis. Annals of Botany 89, 451-458.

Tripathi, S., Sumida, A., Ono, K., Shibata, H., Uemura, S., Kodama, Y., Hara, T., 2006a. Leaf litterfall and decomposition of different above- and belowground parts of birch (Betula ermanii) trees and dwarf bamboo (Sasa kurilensis) shrubs in a young secondary forest in Northern Japan. Biology and Fertility of Soils 43, $237-246$.

Tripathi, S., Sumida, A., Ono, K., Shibata, H., Uemura, S., Takahashi, K., Hara, T., 2006b. The effects of understory dwarf bamboo (Sasa kurilensis) removal on soil fertility in a Betula ermanii forest of northern Japan. Ecological Research 21, 
$315-320$.

Tripathi, S., Sumida, A., Shibata, H., Uemura, S., Ono, K., Hara, T., 2005. Growth and substrate quality of fine root and soil nitrogen availability in a young Betula ermanii forest of northern japan: Effects of removal of understory dwarf bamboo (Sasa kurilensis). Forest Ecology and Management 212, 278-290.

Uemura, S., 1993. Forests and plants of Hokkaido: floral dynamics and ecology of mixed conifer-hardwood forest zone. In: Higashi, S., Osawa, A., Kanagawa, K. (Eds.), Biodiversity and Ecology in the Northernmost Japan. Hokkaido University Press, Sapporo, pp. 21-35.

Umeki, K., 2003. The regeneration of natural forests on Hokkaido, northern Japan: results of scarification and problems remaining to be solved. Journal of Japanese Forestry Society 85, 246-251.

Utsugi, H., 1999. Angle distribution of foliage in individual Chamaecyparis obtusa canopies and effect of angle on diffuse penetration. Trees 14, 1-9.

Wang, X., Guo, Y., Li, B., Wang, X., Ma, Y., 2006. Evaluating a three dimensional model of diffuse photosynthetically active radiation in maize canopies. International Journal of Biometeorology 50, 349-357.

Waring, R. H., Running, S. W., 1998. Forest ecosystems: analysis at multiple scales. Academeic Press, San Diego, USA. 
Weiss, M., Baret, F., Smith, G. J., Jonckheere, I., Coppin, P., 2004. Review of methods for in situ leaf area index (LAI) determination Part II. Estimation of LAI, errors and sampling. Agricultural and Froest Meteorology 121, 37-53.

Yoshida, T., Iga, Y., Ozawa, M., Noguchi, M., Shibata, H., 2005. Factors influencing early vegetation establishment following soil scarificationin a mixed forest in northern Japan. Canadian Journal of Forest Research 35, 175-188. 
Table 1. Leaf area index (LAI) and canopy production and evapotranspiration estimated by horizontal foliage canopy (HFC) model, LAI-2000, Gibbs foliage canopy(GFC) model (sample size: 30, mean $\pm \mathrm{SD}$ ), and litter analysis.

\begin{tabular}{rcccc} 
& HFC & LAI-2000 & GFC & Litter \\
\hline LAI & 2.00 & $3.43 \pm 0.36$ & $4.54 \pm 0.044$ & 5.56 \\
$\begin{array}{r}\text { photosynthesis } \\
\left(\mu \text { mol CO }_{2} \mathrm{~m}^{-2} \mathrm{~s}^{-1}\right)\end{array}$ & 13.0 & - & $21.7 \pm 0.067$ & - \\
$\begin{array}{r}\text { transpiration } \\
\left(\text { mmol H}_{2} \mathrm{O} \mathrm{m}^{-2} \mathrm{~s}^{-1}\right)\end{array}$ & 3.58 & - & $7.21 \pm 0.049$ & - \\
\hline
\end{tabular}




\section{Figure Legends}

Fig.1 The schema of the spatial structure used for measuring and simulating the distribution of photosynthetically active photon flux density (PPFD) in a Betula stand of the Moshiri research plot. (a) Coordinate system of the box set including 1452 boxes. The triangles represent photosensors. The base plane of the box set is at height $180 \mathrm{~cm}$ above ground surface. (b) Box, the unit of light measurement and prediction for foliage. The photosensor of each box is located at the center of the base plane of the box.

Fig.2 The positional relationship among the focal box $b$ and its upper boxes, $b+\left\{\delta_{1}, \delta_{2}, \cdots, \delta_{5}\right\}$. The cones are the photosensors. The shaded region represents the light corridor $C_{b, \delta}$ between boxes $b$ and $b+\delta_{5}$. The disks in the light corridor are the foliage units included in $C_{b, \delta}$.

Fig.3 A photon flux from direction $\delta$ used in the PPFD simulation. Superscript $k$ denotes foliage configuration $k$. (a) $O_{b+\delta, \delta}^{(k)}$ and $O_{b, \delta}^{(k)}$ denote the output of photons from boxes $b+\delta$ and $b$, respectively. $I_{b, \delta}^{(k)}$ is the input of photons at the photosensor of box $b$ from direction $\delta$. (b) Direction vectors. $\delta, \delta_{b}$, and $\delta_{f}$ are direction vector from box $b$ to an upper box, the unit normal vectors of the base plane of box $b$, and the unit normal vector of a foliage unit, respectively. 
Fig.4 The schema of the transition between the foliage configurations $k$ and $k^{\prime}$ by the change in the location of a foliage unit $f$ in the MCMC simulation. The transition from $k$ to $k^{\prime}$ is referred to as a foliage increment $(+f)$, whereas the transition from $k^{\prime}$ to $k$ is referred to as a foliage decrement $(-f)$. The change in $f$ affects not only the PPFD at the box including $f$, but also the boxes located below the box including $f$ by the transport of light.

Fig.5 The foliage configuration of the horizontal foliage canopy model (LAI = 2.00). (a) The foliage configuration estimated from the Moshiri data (observed RPPFD pattern). As defined in the study, the area of the foliage unit (disk) increases with the difference between the R-PPFD above and below the foliage unit. (b) The relationship between the observed and predicted R-PPFD at each photosensor. The R-PPFDs are renormalized to lie in the range between 0 and 1400 $\mu \mathrm{mol}$ photons $\mathrm{m}^{-2} \mathrm{~s}^{-1}$

Fig.6 The foliage configuration of the Gibbs foliage canopy model sampled at 1300K MCMC step $(\mathrm{LAI}=4.60)$. (a) A sample of foliage configuration. The radius of foliage unit (disk) is fixed at $5 \mathrm{~cm}$. (b) The relationship between the observed and predicted R-PPFD at each photosensor. The R-PPFDs are renormalized to range between 0 and $1400 \mu \mathrm{mol}$ photons $\mathrm{m}^{-2} \mathrm{~s}^{-1}$. 
Fig.7 The Histograms of the height and zenith angles of the foliage units that are included in the sample configuration of the Gibbs foliage model shown in Fig.6(12751 foliage units). (a) Histogram of the height of the foliage units. Note that $z=0$ is $180 \mathrm{~cm}$ above the ground surface. (b) Histogram of the zenith angles of the normal vector of foliage units. A foliage unit is horizontal if the zenith angle of its normal vector is zero, whereas it becomes more vertical as the zenith angle increases.

Fig.8 The results of MCMC sampling of the Gibbs canopy model. (a) MCMC step trace of leaf area index (LAI). The 30 open circles indicate the sampling steps and sampled values. (b) The posterior distribution (histogram) of LAI.

Fig.9 The curves of photosynthetic and transpiration rates estimated based on the measurements of five leaves whose mean values are indicated by circles. The parameter estimates are described in the text. (a) The relationship between PPFD and photosynthetic rate (A) functional form is given by Eq.1. (b) The relationship between PPFD and transpiration rate (E) functional form is given by Eq.2. 
Fig.1

(a)
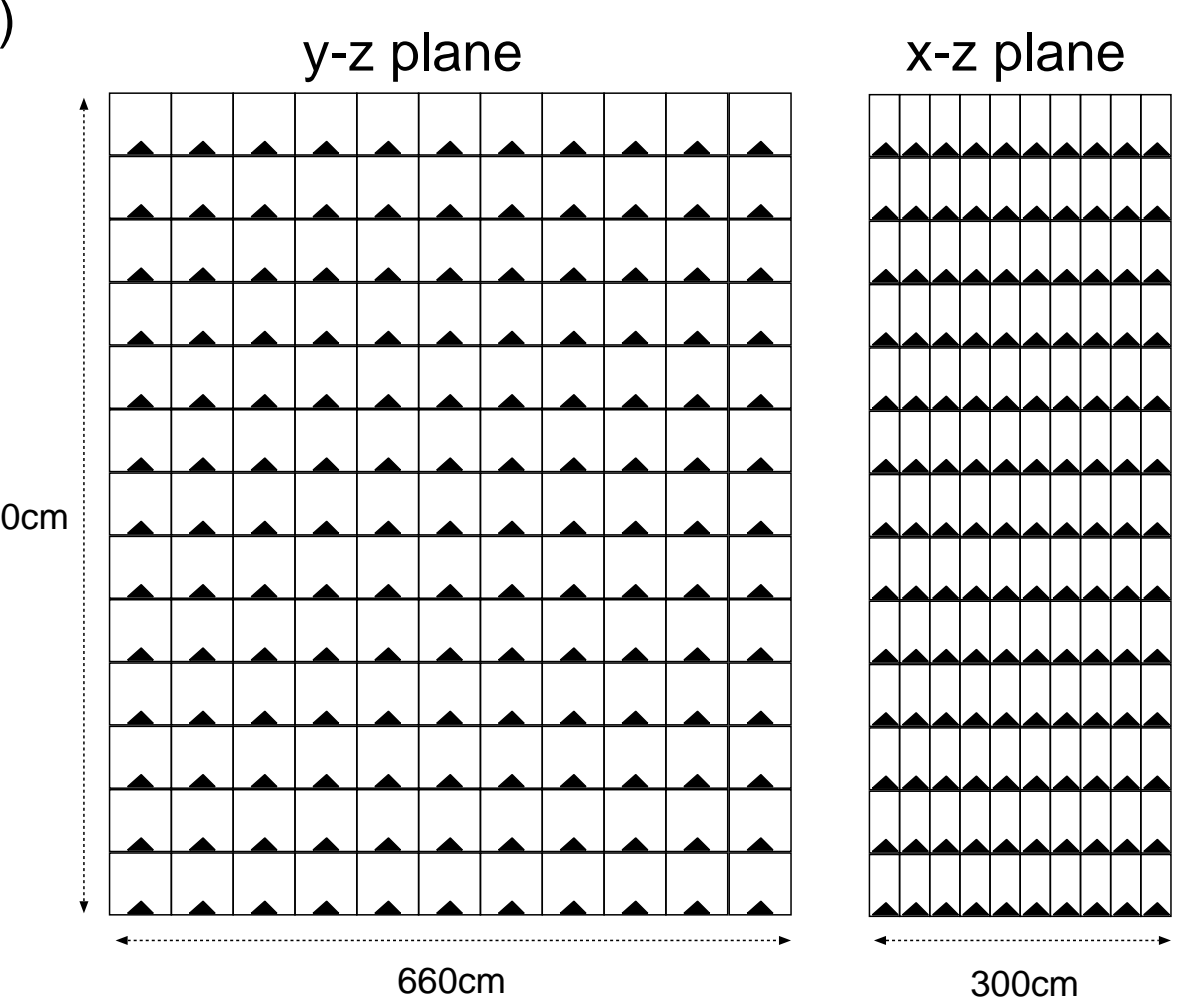

(b)

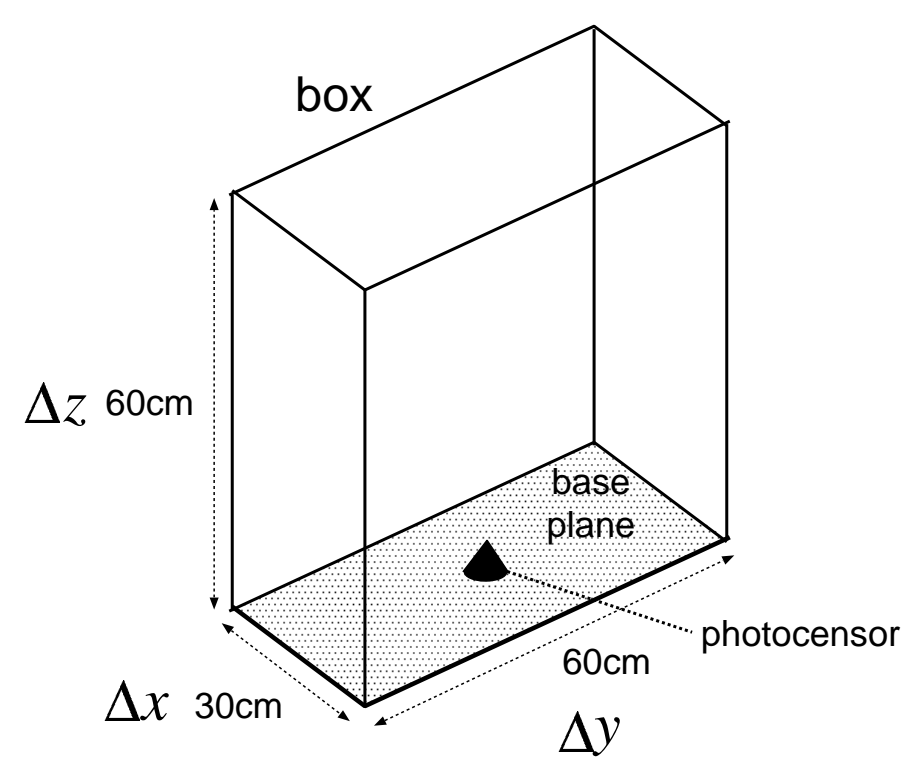


Fig.2

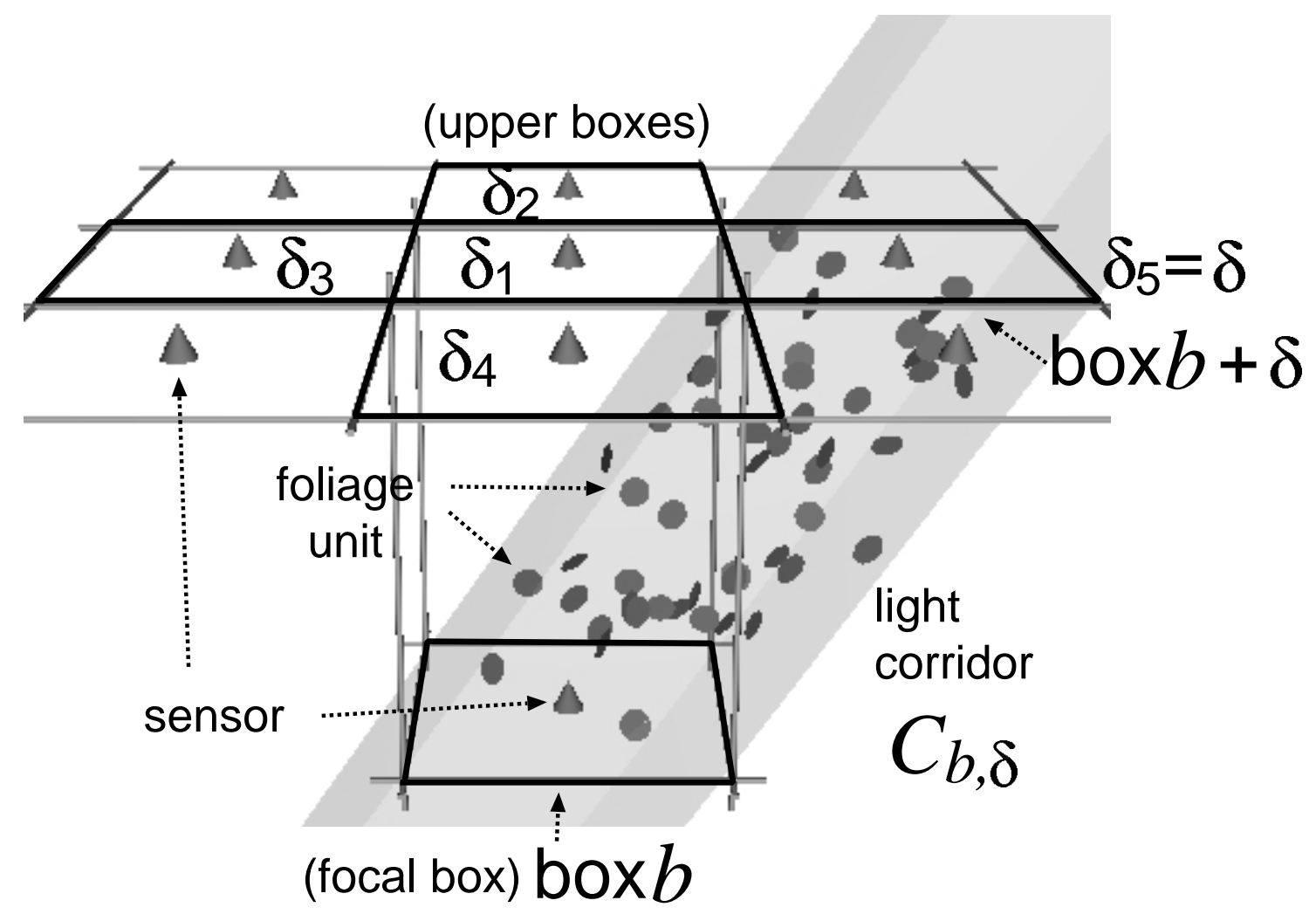


Fig.3

(a)

box $b+\delta$
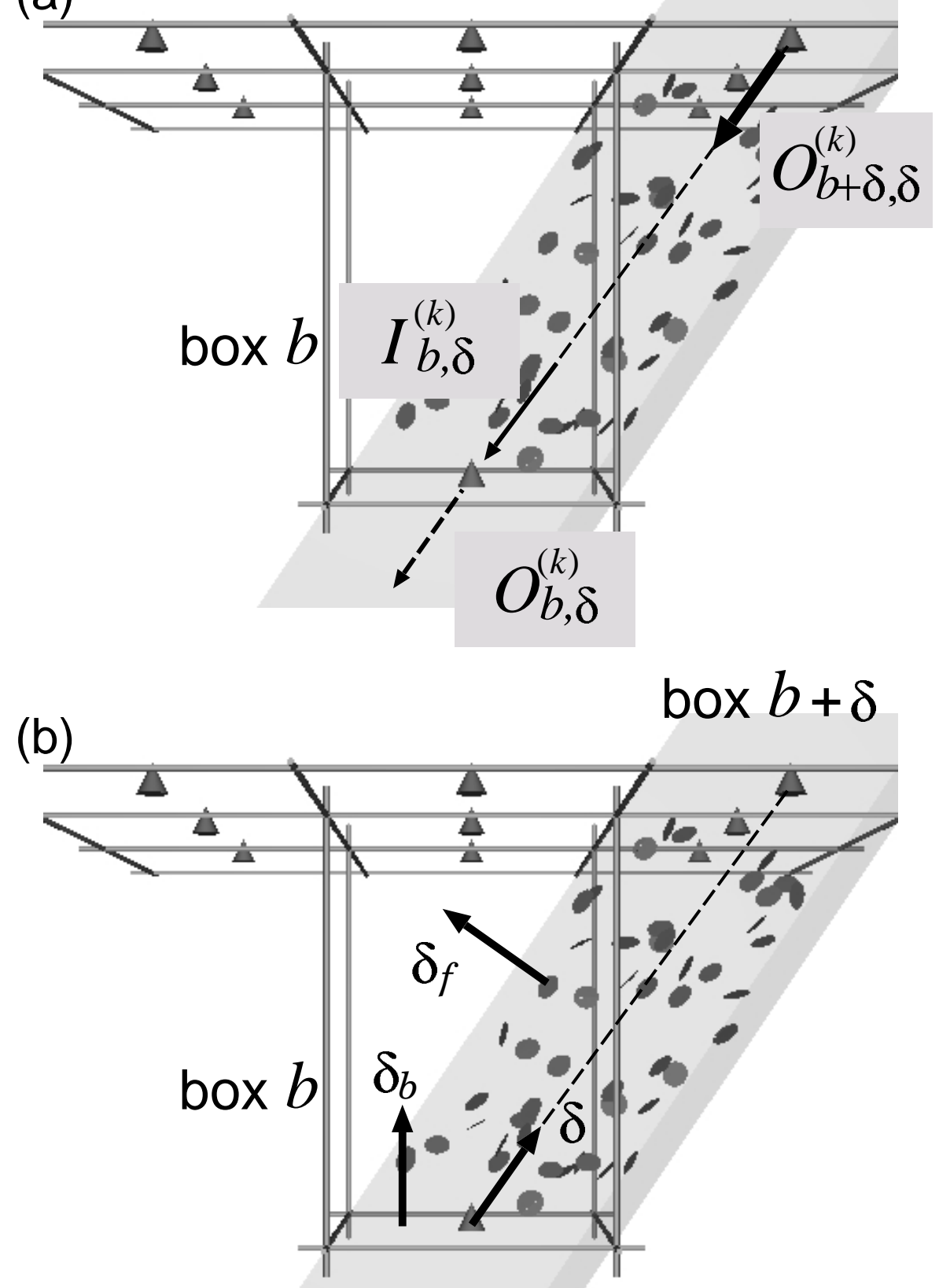
Fig.4
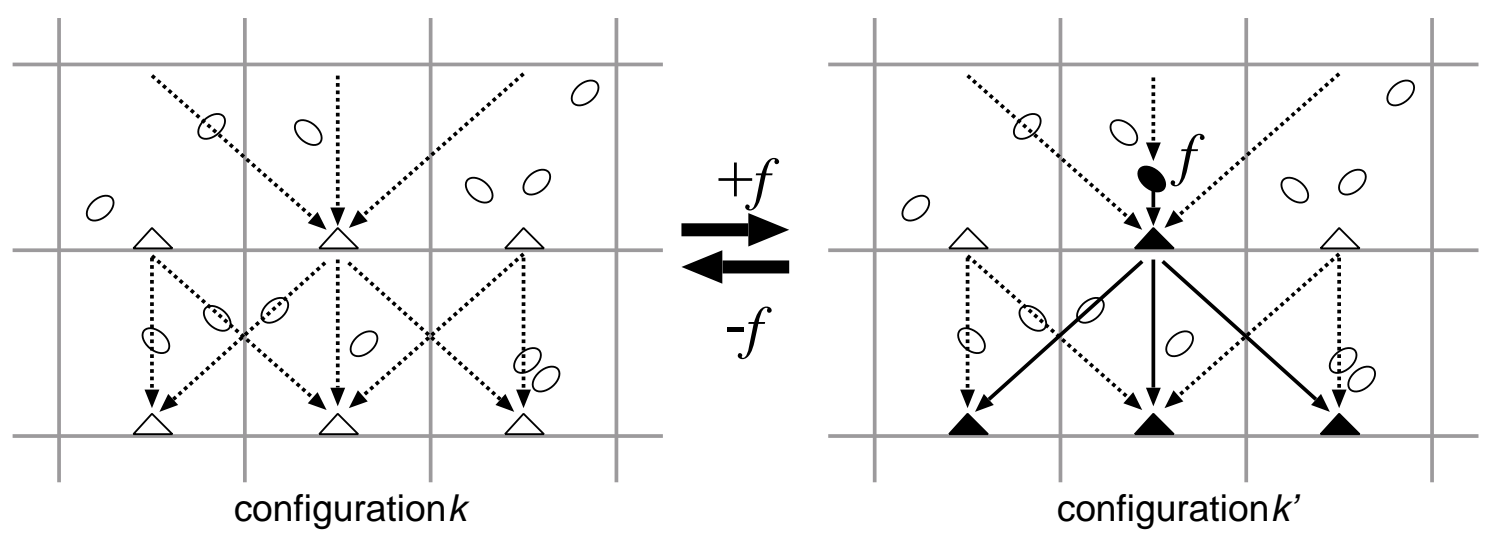
Fig.5

(a)

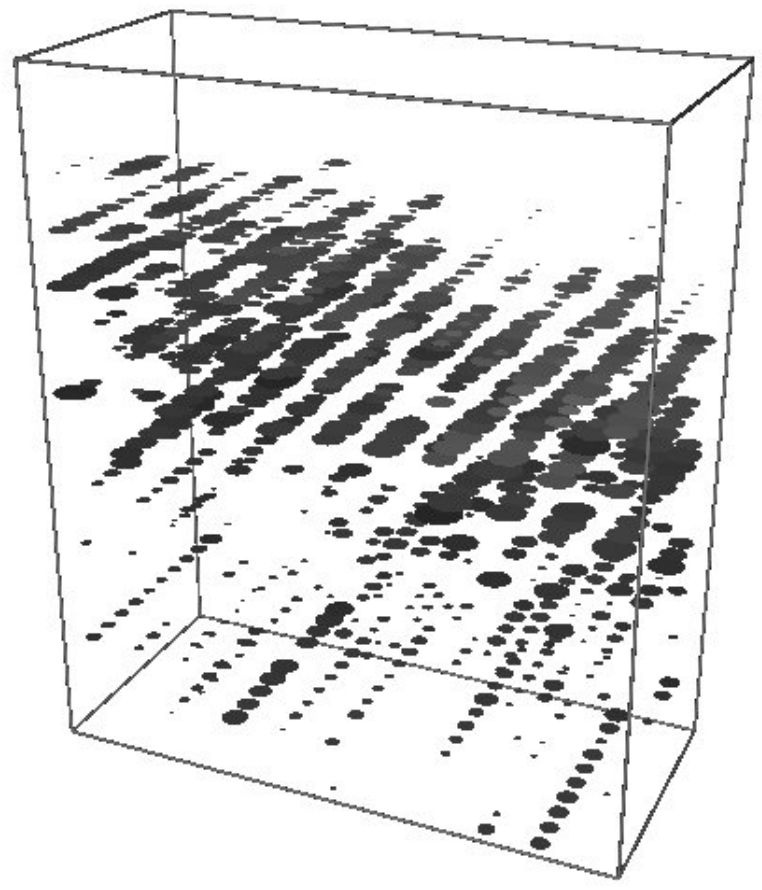

(b)

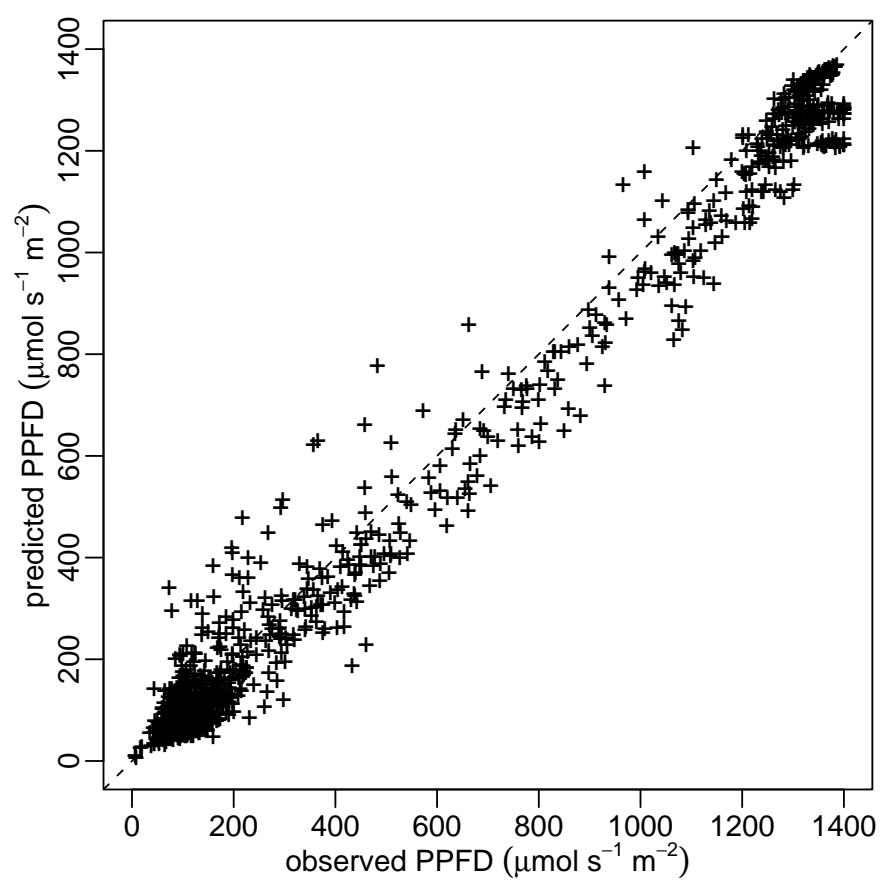


Fig.6

(a)

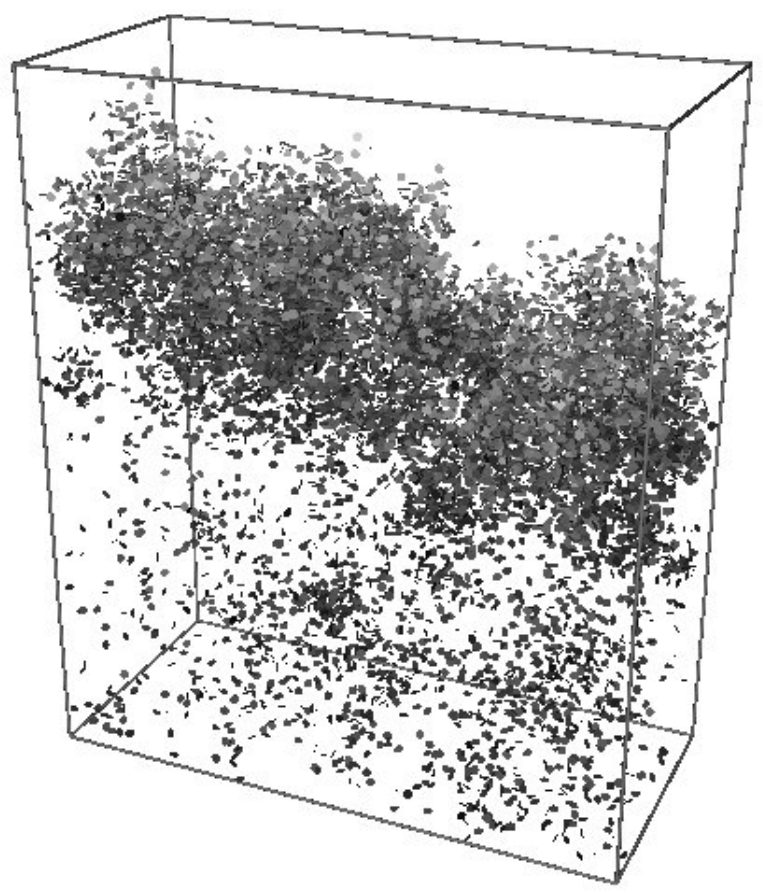

(b)

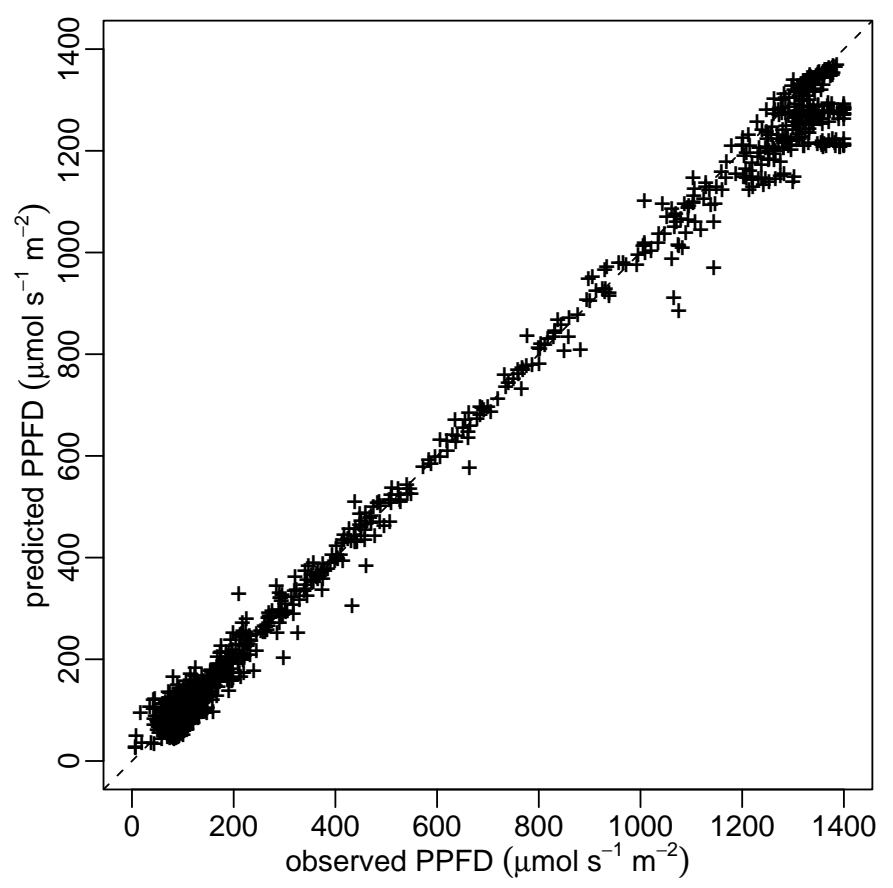


Fig.7

(a)

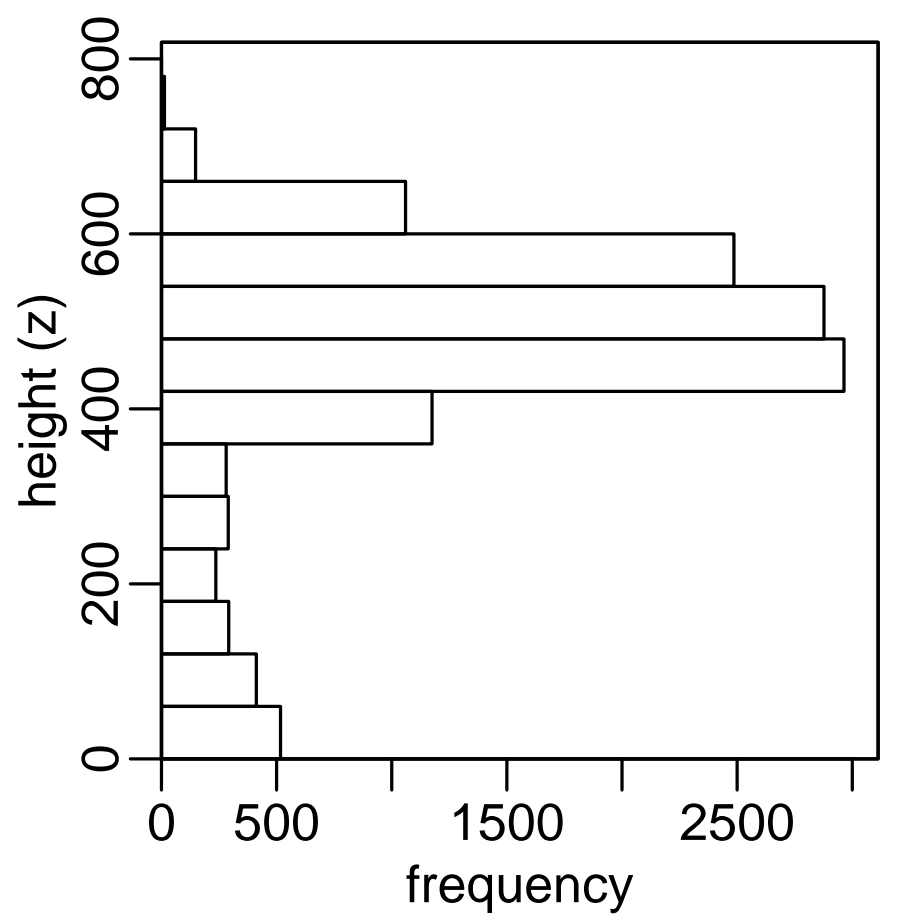

(b)

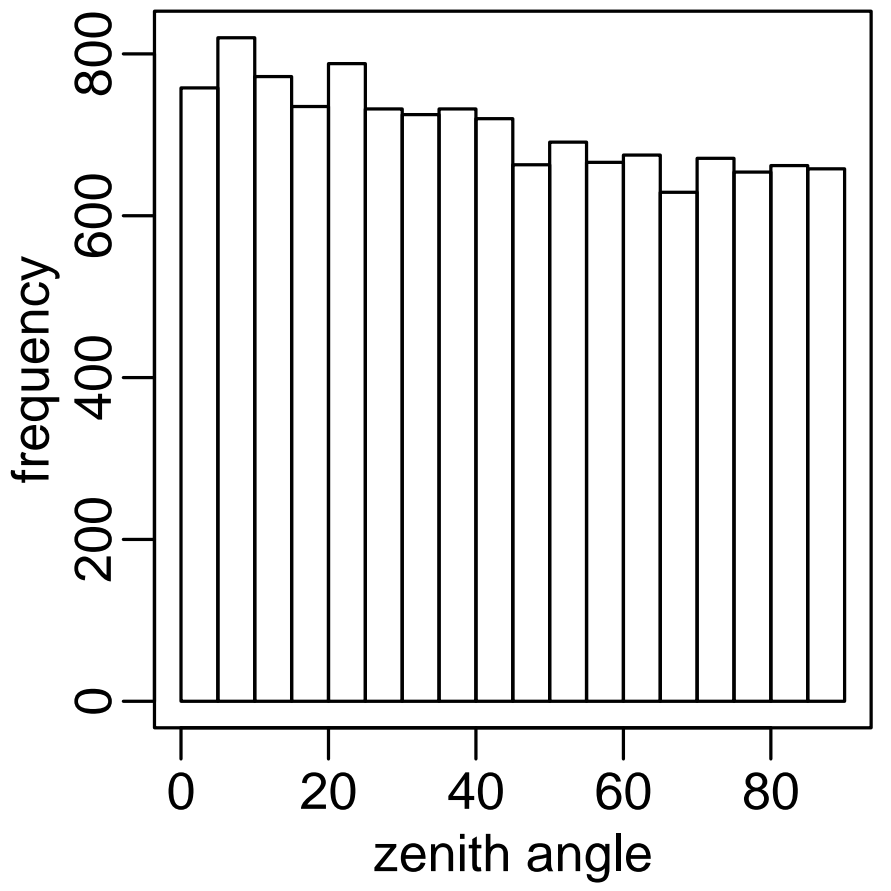


Fig.8

(a)

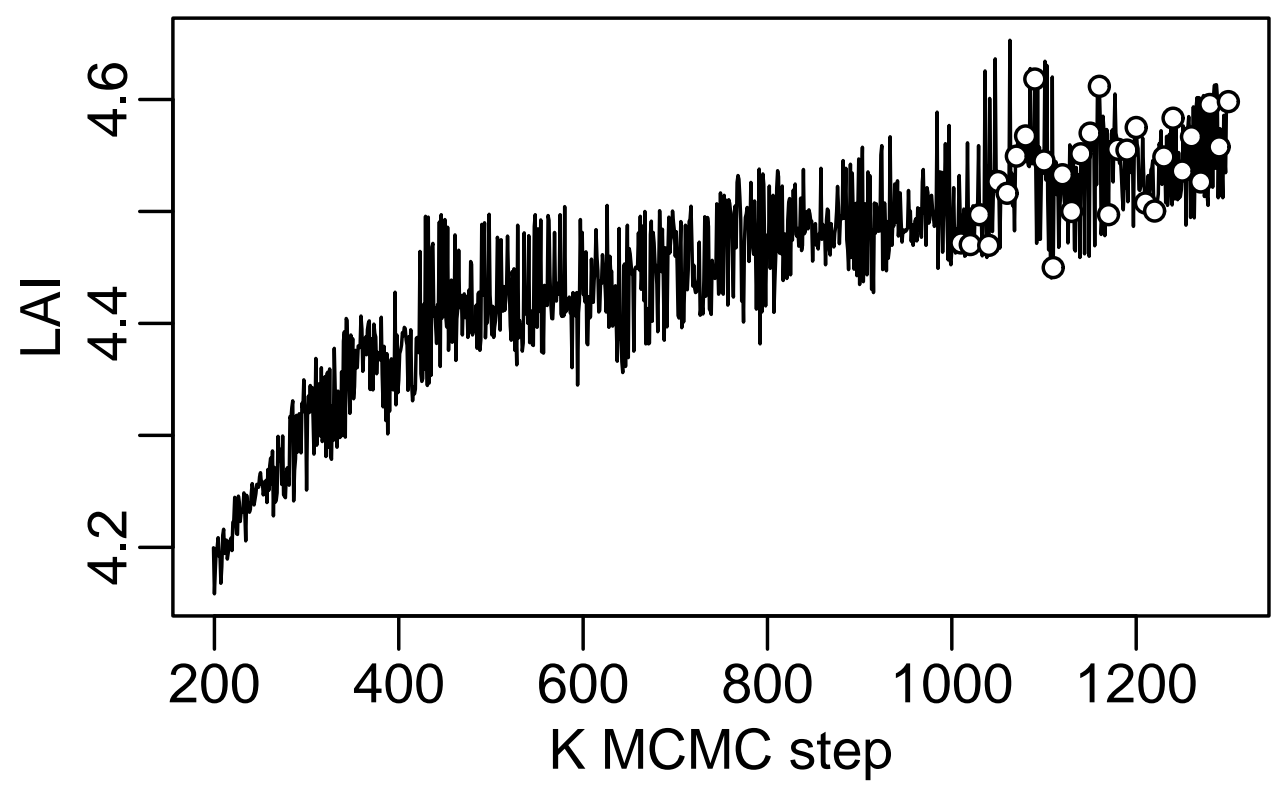

(b)

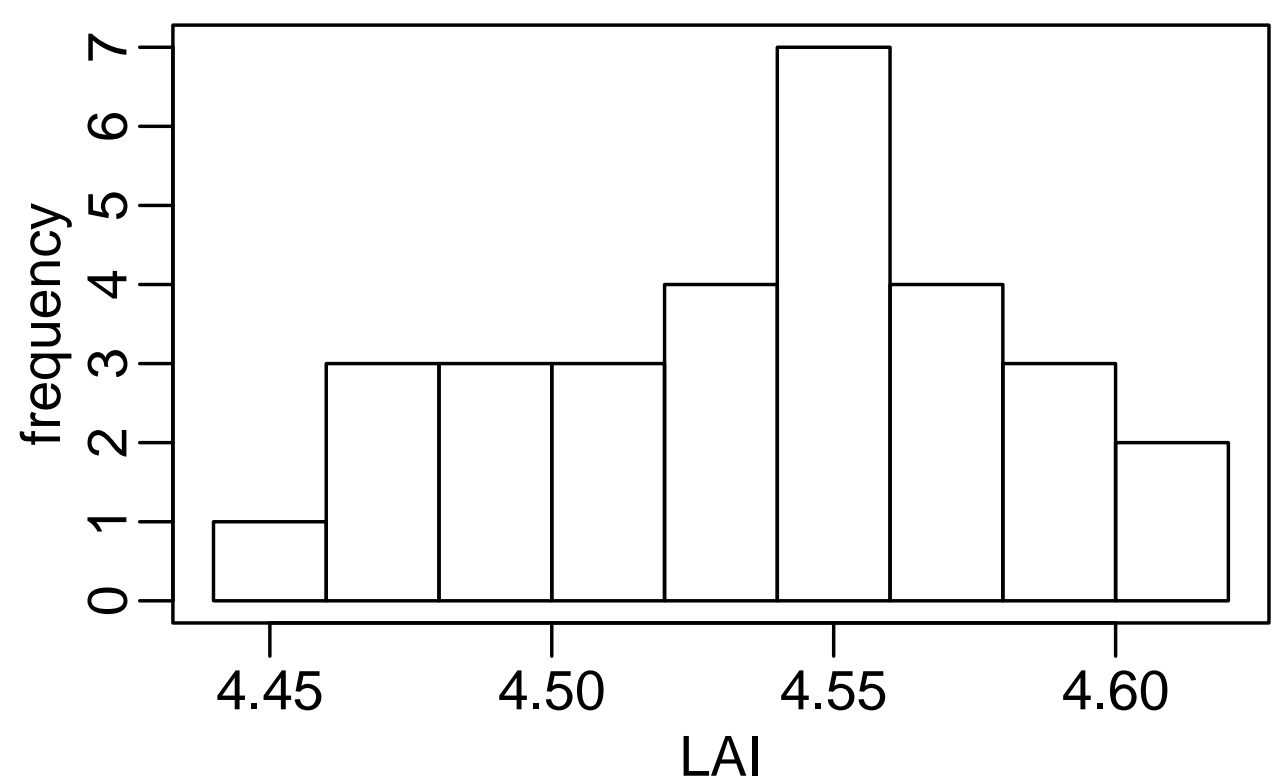


Fig.9

(a)

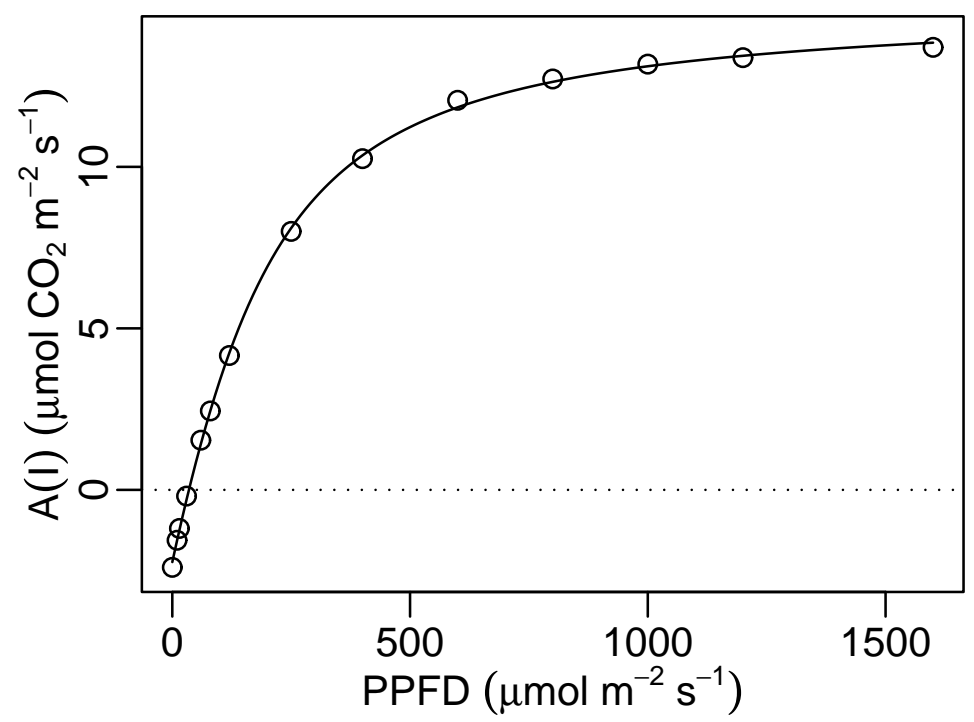

(b)

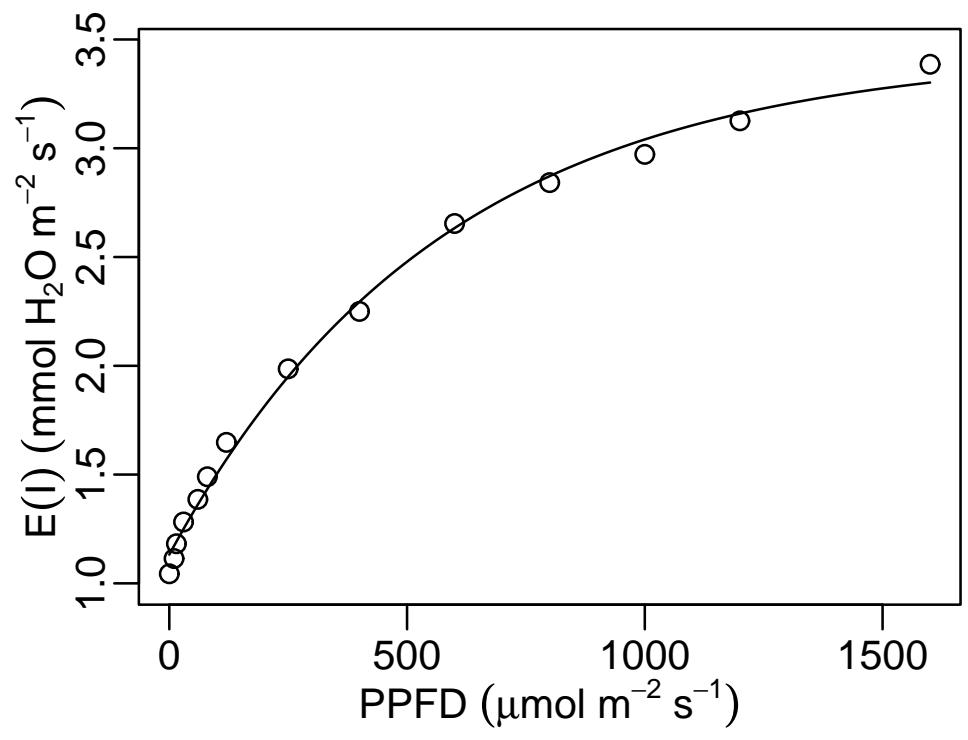

